\title{
Impact of energetic particle precipitation on stratospheric polar constituents: an assessment using monitoring and assimilation of operational MIPAS data
}

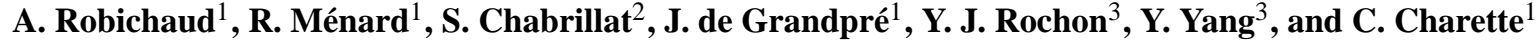 \\ ${ }^{1}$ Atmospheric Science and Technology Directorate, Environment Canada, 2121 Trans-Canada Highway, \\ H9P 1J3, Dorval (Québec), Canada \\ ${ }^{2}$ Belgium Institute for Space Aeronomy, Avenue Circulaire 3, 1180, Bruxelles, Belgium \\ ${ }^{3}$ Atmospheric Science and Technology Directorate, Environment Canada, 4905 Dufferin Street, \\ M3H 5T4, Toronto, Ontario, Canada
}

Received: 23 September 2009 - Published in Atmos. Chem. Phys. Discuss.: 23 October 2009

Revised: 28 January 2010 - Accepted: 4 February 2010 - Published: 16 February 2010

\begin{abstract}
In 2003, strong energetic particle precipitation (EPP) events occurred producing massive amounts of ionization which affected the polar region significantly perturbing its chemical state down to the middle stratosphere. These events and their effects are generally left unaccounted for in current models of stratospheric chemistry and large differences between observations and models are then noted. In this study, we use a coupled 3-D stratospheric dynamicalchemical model and assimilation system to ingest MIPAS temperature and chemical observations. The goal is to gain further understanding of assimilation and monitoring processes during EPP events and their impacts on the stratospheric polar chemistry. Moreover, we investigate the feasibility of assimilating valid "outlier" observations associated with such events. We use $O m F$ (Observation minus Forecast) residuals as they filter out phenomena well reproduced by the model (such as gas phase chemistry, transport, diurnal and seasonal cycles) thus revealing a clear trace of the EPP. Inspection of $O m F$ statistics in both passive (without chemical assimilation) and active (with chemical assimilation) cases altogether provides a powerful diagnostic tool to assess the model and assimilation system. We also show that passive $\mathrm{OmF}$ can permit a satisfactory evaluation of the ozone partial column loss due to EPP effects. Results suggest a small but significant loss of 5-6 DU (Dobson Units) during an EPP-IE (EPP Indirect Effects) event in the Antarctic winter of 2003, and about only $1 \mathrm{DU}$ for the SPE (Solar Proton Event) of
\end{abstract}

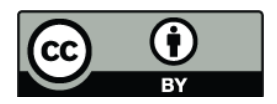

Correspondence to: A. Robichaud (alain.robichaud@ec.gc.ca)
October/November 2003. Despite large differences between the model and MIPAS chemical observations $\left(\mathrm{NO}_{2}, \mathrm{HNO}_{3}\right.$, $\mathrm{CH}_{4}$ and $\mathrm{O}_{3}$ ), we demonstrate that a careful assimilation with only gas phase chemistry included in the model (i.e. no provision for EPP) and with relaxed quality control nearly eliminated the short-term bias and significantly reduced the standard deviation error of the constituents below $1 \mathrm{hPa}$.

\section{Introduction}

It has been known for a long time that the main source of global stratospheric $\mathrm{NO}_{\mathrm{x}}$ is the oxidation of $\mathrm{N}_{2} \mathrm{O}$ from the troposphere. However, energetic particle precipitation (EPP) is considered as the most important secondary source. These particles are either high energetic electrons or protons that can produce NO directly in the stratosphere if their energies are respectively greater than $300 \mathrm{keV}$ and $30 \mathrm{MeV}$ (Randall et al., 2006). EPP, solar and galactic cosmic rays which penetrate into the polar middle atmosphere at high latitudes give rise to ionization, dissociation, dissociative ionization and excitation processes (Brasseur and Solomon, 2005; Jackman et al., 2008). EPP exerts a larger influence on polar ozone on a decadal scale than previously thought (Sinnhuber et al., 2006). On short to medium time scales, EPP influences the production of odd hydrogen $\left(\mathrm{HO}_{\mathrm{x}}\right)$ and odd nitrogen $\left(\mathrm{NO}_{\mathrm{y}}\right)$ which can affect ozone chemistry through chemical catalytic cycles (Solomon and Crutzen, 1981; Brasseur and Solomon, 2005; Turunen et al., 2009). The high values of $\mathrm{NO}_{\mathrm{x}}$ (NO, $\left.\mathrm{NO}_{2}\right)$ and $\mathrm{HO}_{\mathrm{x}}\left(\mathrm{H}, \mathrm{OH}, \mathrm{HO}_{2}\right)$ produced by $\mathrm{EPP}$, which can descend in the mesosphere and upper stratosphere at polar

Published by Copernicus Publications on behalf of the European Geosciences Union. 
latitudes $\left(>60^{\circ}\right)$ of both hemispheres, have been the subject of many controversies, particularly in the way they affect the ozone budget. Significant photochemical loss has been reported by many authors in the upper stratosphere associated with these disturbances (for general discussion see Callis et al., 1996; Jackman and McPeters, 2004; Rozanov et al., 2005; Seppälä et al., 2007; WMO, 2007). For example, during a very strong solar proton event in July 2000, measurements from the UARS HALOE and NOAA 14 SBUV/2 instruments indicated short-term (time scale of a day) middle mesospheric ozone decreases of over $70 \%$ caused by short-lived $\mathrm{HO}_{\mathrm{x}}$ during the event with a medium-term (several days) upper stratospheric ozone depletion of up to $9 \%$ caused by longer-lived $\mathrm{NO}_{\mathrm{x}}$ (Jackman et al., 2001). With the use of a 3-D numerical model, Rozanov et al. (2005) showed that atmospheric chemistry throughout the whole atmosphere down to the surface is significantly perturbed by EPP indirect effects (thereafter referred to as EPP-IE following Randall et al., 2006). EPP-IE is linked with ionized particles trapped in the magnetosphere which precipitate into the upper atmosphere. Such particles originated in the solar wind or were ejected during solar disturbance.

Evidence of high amounts of upper stratospheric and mesospheric polar $\mathrm{NO}_{2}$ and anomalous values of $\mathrm{HNO}_{3}$ as measured by the MIPAS/ENVISAT mission (Fischer and Oelhaf, 1996; ESA, 2000; Fischer et al., 2008) have been documented in the recent literature (Funke et al., 2005; Orsolini et al., 2005; Stiller et al., 2005; Verronen et al., 2008). Anomalous but continuous downward transport of these chemical constituents from the mesosphere and lower thermosphere (MLT) region into the upper stratosphere starting from the end of May and extending to September 2003 was found to be linked to several geomagnetic and EPPIE events occurring in a rather continuous fashion in the MLT (Funke et al., 2005; Stiller et al., 2005). On the other hand, a more spectacular event such as a SPE (solar proton event) had also occurred the same year towards to end of October 2003 (referred as the "Hallowe'en storm"; see Baker et al., 2004). SPEs which are rather sporadic in nature occur more frequently near the solar maximum or during its declining phase. They have recently been widely documented both with models (Semeniuk et al., 2005; Jackman et al., 2008 and references therein; Vogel et al., 2008) and in observational studies (Lopez-Puertas, 2005; Orsolini et al., 2005). SPEs are specifically linked with solar flares and/or coronal mass ejections. Both types of EPP (EPP-IE and SPE) could be modulated by meteorological conditions influencing the downward transport of chemical constituents to the stratosphere (Randall et al., 2006, 2007; Siskind et al., 2007). The rate of descent at high latitudes is linked to the strength of the polar vortex (Manney et al., 1994; Seppälä et al., 2004) and possibly enhanced at times by a complex combination of dynamical factors and coupling between the stratosphere and the mesosphere as discussed in Siskind et al. (2007). Accompanying the high $\mathrm{NO}_{\mathrm{x}}$ are anomalously high $\mathrm{HNO}_{3}$ values in the polar stratosphere (Orsolini et al., 2005) which could be explained by ion cluster chemistry reactions (Kawa et al., 1995; McDonald et al., 2000; de Zafra and Smyshlyaev, 2001), by ion-ion recombination (Verronen et al., 2008) and/or by heterogeneous reactions of $\mathrm{NO}_{\mathrm{x}}$ on sulphate aerosols via $\mathrm{N}_{2} \mathrm{O}_{5}$ or, less likely, by simple gas phase reactions (see Stiller et al., 2005 for a discussion). $\mathrm{HO}_{\mathrm{x}}$ and $\mathrm{NO}_{\mathrm{x}}$ gases have a short chemical lifetime since they are mainly destroyed by photo-dissociation. But during the polar winter, when little or no sunlight is available, the impacts of $\mathrm{NO}_{\mathrm{x}}$ can survive longer and even extend outside the polar region through downward transport processes across the stratopause, thus affecting more significantly the total ozone column.

In our study, we use a new comprehensive coupled stratospheric chemistry-meteorology 3-D global model called GEM-BACH (Ménard et al., 2007; hereafter M2007) together with operational MIPAS retrievals. We calculate the mean and standard deviation of passive (without chemical assimilation) versus active (with chemical assimilation) $\mathrm{OmF}$ (observation minus forecast) residuals of long-lived species $\left(\mathrm{O}_{3}, \mathrm{NO}_{2}, \mathrm{HNO}_{3}\right.$ and $\left.\mathrm{CH}_{4}\right)$ during the second half of 2003. EPP events are not physically accounted for in our model but we demonstrate that the signature of these tracers can be correctly identified by passive $O m F$ plots in observation space as shown in Sect. 4 when downward transport of excess $\mathrm{NO}_{\mathrm{y}}$ occurs. Throughout this study, a comparison is also made with the case that includes chemical assimilation (active $O m F$ ). Together, these sets of cross sections (passive and active $O m F$ s) constitute an excellent diagnostic and monitoring tool for model-assimilation systems. They help to track the signature of EPP and other related phenomena (such as heterogeneous ion-cluster chemistry involving water) which are not taken into account in most stratospheric models. Our study also addresses several aspects related to the data assimilation methodology itself and derived diagnostics, more specifically that:

1. the demonstration on both theoretical and experimental basis that our assimilation system almost eliminates the chemical biases and reduces the random error in the case of slow time scale model errors or imprecise initial conditions while having less impact on fast time scale model errors. Note that EPP phenomena are interesting in this context because, among other things, they produce impacts of various time scales,

2. the chemical assimilation of MIPAS-ESA in the context of EPP is successful if careful attention is paid to proper error statistics and quality control,

3. the presentation of a new diagnostic tool (made up of 4 panels) to study the impact of phenomena producing large effects which a priori are not necessarily present in the modeling system and perform an analysis with the $\mathrm{OmF}$ technique. 
In Sect. 2.4 we provide a theoretical derivation explaining the conditions of success of assimilation in the presence of important model chemical biases. The methods and diagnostics are described in Sect. 3 and the results and applications in Sect. 4. An evaluation of ozone loss due to the EPP during the second half of 2003 is also performed using $O m F$ diagnostics. Note that the $\mathrm{OmF}$ technique is considered here as a complementary method to the existing ones to evaluate polar ozone loss due to EPP effects (see Sect. 4.4). Finally, Sect. 5 presents a summary and the conclusions.

\section{GEM-BACH model, data assimilation system and observations}

\subsection{Model}

We use the model GEM-BACH v3.3.0 (Global Environmental Multi-scale coupled with the Belgium Atmospheric CHemistry), which has emerged from a collaboration between Canada and Belgium. It is a comprehensive 3-D global chemistry circulation model (GCCM) based on the stratospheric version of the Canadian NWP model called GEM (Côté et al., 1998) and the stratospheric chemistry developed for BASCOE (Errera and Fonteyn, 2001). The coupled model allows chemistry-radiative feedbacks (M2007; de Grandpré et al., 2009). The model has 80 vertical levels, including 27 in the stratosphere, and is integrated at a horizontal resolution of $1.5^{\circ}$ by $1.5^{\circ}$ (a grid of 240 by 120) with a lid at $0.1 \mathrm{hPa}$, allowing stratospheric channels of TOVS (AMSU-A channels 9-14) and MIPAS observations (mostly stratospheric) to be assimilated. The vertical resolution of the model ranges from 0.5 to $3 \mathrm{~km}$ in the stratosphere (with $\sim 1.5 \mathrm{~km}$ at $30 \mathrm{~km}$ ) and $3-4 \mathrm{~km}$ in the lower mesosphere, with a higher resolution in the troposphere. Semi-implicit and semi-Lagrangian numerical techniques optimized to handle a large number of advection equations for the transport of species are utilized by the model (a more complete description is available in M2007). On the other hand, an on-line coupled comprehensive stratospheric chemistry module developed at the Belgium Institute of Aeronomy (Errera and Fonteyn, 2001) has been implemented in our framework. It includes 57 species which interact through 143 gas-phase reactions, 48 photolysis reactions and 9 heterogeneous reactions. The chemistry package is built with the Kinetic Preprocessor (Damian et al., 2002) and the scheme is integrated using a third order Rosenbrock solver (Hairer and Wanner, 1996). The chemical and photo-dissociation rates follow the Jet Propulsion Laboratory compilation by Sander et al. (2003). The heterogeneous chemistry is parameterized as a simple function of temperature and a prescribed climatology for sulfate area densities. Polar Stratospheric Clouds (PSC) are formed when temperatures are below $194 \mathrm{~K}$ (NAT particles) or $186 \mathrm{~K}$ (ice particles). This photochemical module was used operationally in BASCOE and has been fully validated (see M2007). Only gas phase and heterogeneous chemistry are represented in our model. Therefore, no provisions for ion, ion production/recombination, ion-neutral coupling or ion-cluster chemistry exist in our framework which would be required in principle to fully simulate EPP effects.

\subsection{Assimilation system}

The assimilation algorithm is a variational 3D-VAR 6-h cycle (Gauthier et al., 1999) with calculation of $O m F$ (observation minus forecast) using the model forecasts at the time steps nearest to the observation times, i.e. FGAT (First Guess at Appropriate Time). The latter approach was selected since it permits a better time resolution than that of the standard 3D-VAR, which is crucial for fast time scale assimilated constituents such as $\mathrm{NO}_{2}$ in the middle atmosphere (M2007). Error statistics needed for the assimilation algorithm have been built using the NMC method (Parrish and Derber, 1992) for the dynamics. The method of H-L (Hollingsworth and Lönnberg, 1986) adapted for satellite measurements (see M2007) was applied in setting the constituent error variances. The error correlations for constituents were estimated from 6-h time differences of fields from a standard model run (Polavarapu et al., 2005). The set of operational MIPAS chemical constituents and temperature observations presented to the minimization algorithm is obtained after filtering outliers using the quality check applied operationally at CMC (Canadian Meteorological Center), which rejects data whenever $O m F$ residuals are greater than 5 times the estimated $O m F$ standard deviations. This is considered as a relaxed gross error check as compared to the value of 3 traditionally used (Gauthier et al., 2003). Special treatment of the assimilation error statistics has to be applied so that the observed high values of $\mathrm{NO}_{\mathrm{y}}$ produced by EPP do not get filtered out by the quality control such as in Errera et al. (2008). The resulting transport and dynamics in our system has been verified in M2007 with independent data and found to be very reliable in both the troposphere and stratosphere in situations with and without EPP effects.

\subsection{MIPAS/ENVISAT observations}

The MIPAS (Michelson Interferometer for Passive Atmospheric Sounding) instrument was launched on 1 March 2002 onboard ESA's ENVISAT (European Space Agency ENVironmental SATellite), which is a sun-synchronous polarorbiting satellite flying at about $800 \mathrm{~km}$ altitude with a $98.55^{\circ}$ inclination. MIPAS provides day and night time measurements from pole to pole, which allows observation of the Arctic and the Antarctic areas during the polar vortex season. In particular, the simultaneous observation of $\mathrm{HNO}_{3}$ and $\mathrm{NO}_{2}$ in the polar night makes possible the assessment of chemical transformation within the $\mathrm{NO}_{\mathrm{y}}$ family occurring during EPP events. The MIPAS instrument is a slow downward limb scanning Fourier spectrometer, which measures 
the complete spectrum of limb emission in the frequency interval $680-2410 \mathrm{~cm}^{-1}$ of the mid-infrared spectrum (corresponding to the wavelength range of $4.1-14.5 \mu \mathrm{m}$ ). A spectrum is acquired every $4.6 \mathrm{~s}$ at each of the 17 tangent altitudes giving about 1000 profiles per day, starting at an altitude of $68 \mathrm{~km}$ down to $6 \mathrm{~km}$. The average number of orbits is 14.4 per day. The field of view at the tangent heights is $\sim 3 \mathrm{~km}$ by $30 \mathrm{~km}$ with a resolution of $500 \mathrm{~km}$ along track and about $2800 \mathrm{~km}$ across track at the Equator. The vertical resolution is about $3 \mathrm{~km}$ in the stratosphere but becomes larger in the mesosphere (Fischer et al., 2008).

The retrieved profiles for this study have been obtained by non-linear least square fitting using the Optimized Retrieval Model (ORM), which has the advantage of maximum vertical resolution but has the disadvantage of the possibility of oscillatory profiles. The main challenge of the ORM has been the requirement of performing the complex operation of mathematical inversion in near real time for a large number of data (Fischer et al., 2008). Other options exist, such as more accurate retrievals performed by IMK ${ }^{1}$ using Tikhonov regularization, which is more stable than ORM (von Clarmann, 2007). However, MIPAS-IMK retrieval products are not available for all measurement days, as opposed to the MIPAS-ESA products.

The validation of MIPAS-ESA observations (version 4.61 of retrieval profiles in near-real time) has been discussed in many papers (Dethof et al., 2004; Cortesi et al., 2007; Ridolfi et al., 2007; see M2007 Chapter 4 for a review). In the stratosphere, comparing MIPAS observations to HALOE (V 19) gives biases of -1 to $+3 \mathrm{~K}$ between the two instruments. In the lower stratosphere, the biases are a little less, that is about 0.5 to $2.5 \mathrm{~K}$ (Dethof et al., 2004). Wang et al. (2005) reported that mean differences with other sources are within $0.5 \mathrm{~K}$ as averages and within $1-1.5 \mathrm{~K}$ at individual levels between 10-30 km. Typical r.m.s errors for ozone were found to be in the range 5-15\% (Dethof et al., 2003; M2007) and for $\mathrm{H}_{2} \mathrm{O}, \mathrm{CH}_{4}, \mathrm{~N}_{2} \mathrm{O}$ and $\mathrm{NO}_{2}$, around 25-35\% (Baier et al., 2005; M2007). Note that, in general, MIPAS-ESA errors in the stratosphere are also acceptable for $\mathrm{NO}_{2}$. Comparison of MIPAS-ESA with MIPAS-IMK has been done very thoroughly and extensively by Wetzel et al. (2007) for $\mathrm{NO}_{2}$ who suggested a general good agreement between the two sets (see Fig. 15, bottom panel, of Wetzel et al. paper). However, according to Funke et al. (2005), $\mathrm{NO}_{2}$ from MIPAS-ESA retrievals is underestimated by $30 \%$ above $50 \mathrm{~km}$, mostly due to physical processes not taken into account by MIPAS-ESA retrievals such as non-LTE (non local thermodynamic equilibrium) processes. During SPE, below $30 \mathrm{~km}$, it is also reported that the MIPAS-ESA retrievals for $\mathrm{NO}_{2}$ could suffer from very large errors (Wetzel et al., 2007). Therefore, in our study, we thus have been careful in not drawing any conclusions for MIPAS operational $\mathrm{NO}_{2}$ or other constituents

\footnotetext{
${ }^{1}$ IMK: Institut für Meteorologie und Klimaforschung, at Karlsruhe, Germany
}

above $0.5 \mathrm{hPa}(50 \mathrm{~km})$, the presence of the model top sponge layer corrupting results at model top in any cases. On the other hand, for $\mathrm{NO}_{2}$ during EPP below about $30 \mathrm{~km}$, no emphasis was put on calculation or diagnosis. Our domain of interest is the middle and upper stratosphere and stratopause regions roughly between the altitude of $30-50 \mathrm{~km}$. Wetzel et al. (2007) also presented comparisons with ACE, HALOE, SAGE II and POAM II and showed fair to very good results with MIPAS-ESA $\mathrm{NO}_{2}$. Discrepancy between the two sets (ESA and IMK) exists but this does not affect our study since $\mathrm{NO}_{2}$ does not enter into $\mathrm{O}_{3}$ loss calculation in the context of our methodology (i.e.: passive $O m F$ of ozone only are used for polar ozone loss calculation, see Sect. 5.4). MIPAS-ESA ozone has been shown to verify well (bias within $\pm 15 \%$ ) in periods with or without EPP (Ménard et al., 2007, chapter 10).

The period under study is the second half of 2003 due to the near continuous day to day availability of MIPAS-ESA operational data during this time. It also happens that 2003 is considered a very active year from the geomagnetic point of view (http:/www.spwc.noaa.gov). The assimilation period extends from the second week of August to the first week of December 2003. Note that in the Northern Hemisphere, the upper stratospheric polar vortex was perturbed from the second half of December (after the end of our analyzed period) and finally broke up in late December associated with a stratospheric sudden warming event (Manney et al., 2005), producing a distortion of the EPP signal.

\subsection{Data assimilation in presence of chemical model biases}

Assimilation schemes generally assume that both model and observations have no systematic errors or biases. However, for a number of reasons, the model may have inadequate or missing representation of some physical processes which can give rise to significant model biases. The presence of model biases (caused by EPP impacts for example) can be detected in the mean observation-minus-forecast residuals. The assimilation of meteorological observations will not eliminate model biases from the analysis and forecasts no matter how the observation and background error statistics are prescribed, unless an additional step is introduced in the assimilation scheme, known as the bias correction (see Dee and daSilva, 1998, or Ménard, 2009, and references therein for further details). In the case of temperature assimilation, a bias correction based on MIPAS temperature using standard procedures has been applied to AMSU-A observations before assimilation (see M2007 for more details). But for chemical constituents no such correction scheme is utilized in this study. We rather argue that careful assimilation of chemical constituents could correct the bias under the circumstances discussed below. As an illustrative example, consider a persistence model for chemical concentrations. 
Suppose that the reality represented here by the true state $\boldsymbol{x}^{t}$ is governed by the following equation,

$\boldsymbol{x}_{n+1}^{t}=\boldsymbol{x}_{n}^{t}+\boldsymbol{q} \Delta t$

where $n$ is the time step and $\boldsymbol{q}$ is the net production rate that is not included in the atmospheric chemistry model (such as caused by EPP impacts) but present in the atmosphere and $\Delta \mathrm{t}$, the time scale. In this context of a model based on persistence, a forecast $\boldsymbol{x}_{n+1}^{f}$ at time $t_{n+1}$ issued from an analysis $\boldsymbol{x}_{n}^{a}$ at time $t_{n}$ takes the simple form

$\boldsymbol{x}_{n+1}^{f}=\boldsymbol{x}_{n}^{a}$

The forecast and analysis error defined as $\boldsymbol{\varepsilon}^{f}=\boldsymbol{x}^{f}-\boldsymbol{x}^{t}$, $\boldsymbol{\varepsilon}^{a}=\boldsymbol{x}^{a}-\boldsymbol{x}^{t}$ are then related by equation (combining Eqs. 1 and 2):

$\boldsymbol{\varepsilon}_{n+1}^{f}=\boldsymbol{\varepsilon}_{n}^{a}-\boldsymbol{q} \Delta t$.

The mean error or bias is then also governed by the equation,

$\overline{\boldsymbol{\varepsilon}}_{n+1}^{f}=\overline{\boldsymbol{\varepsilon}}_{n}^{a}-\boldsymbol{q} \Delta t$,

since $\boldsymbol{q}$ is a deterministic quantity. In general, 3D-VAR (but also Kalman filters and Optimum Interpolation) have the following (unbiased) form (Kalnay, 2003)

$\boldsymbol{x}_{n}^{a}=\boldsymbol{x}_{n}^{f}+\mathbf{K}\left(\boldsymbol{y}_{n}^{o}-\mathbf{H} \boldsymbol{x}_{n}^{f}\right)$

where $\mathbf{K}$ is the Kalman gain matrix, $\mathbf{H}$ is the observation operator which includes interpolation for the observations location to the discrete model representation, and $\boldsymbol{y}_{n}^{o}$ is the observation vector. Assuming that the observations

$\boldsymbol{y}_{n}^{o}=\mathbf{H} \boldsymbol{x}_{n}^{t}+\boldsymbol{\varepsilon}_{n}^{o}$

are unbiased, i.e. $\overline{\boldsymbol{\varepsilon}}_{n}^{o}=0$ and subtracting $\boldsymbol{x}_{n}^{t}$ from Eq. (5) and combining with Eq. (6), leads, after averaging, to

$\overline{\boldsymbol{\varepsilon}}_{n}^{a}=(\mathbf{I}-\mathbf{K H}) \overline{\boldsymbol{\varepsilon}}_{n}^{f}$

Note that $(\mathbf{I}-\mathbf{K H})$ represents the reduction of variance (covariance) due to the assimilation of observations. In a scalar case and in a simplified context of having observations at each grid point, the reduction of variance, that we denote by $m$, is simply

$m=I-K H=\frac{\sigma_{o}^{2}}{\sigma_{f}^{2}+\sigma_{o}^{2}}$,

where $\sigma_{f}^{2}$ and $\sigma_{o}^{2}$ denote respectively the forecast and observation error variances. The following constraint applies on $m$

$0<m<1$

Combining the scalar form of Eqs. (4) and (7) gives an evolution equation for the forecast error bias of the form,

$\bar{\varepsilon}_{n+1}^{f}=-q \Delta t+(I-K H) \bar{\varepsilon}_{n}^{f}$.
In the simplified scalar case above, (i.e., Eq. 8), we have

$\bar{\varepsilon}_{n+1}^{f}=-q \Delta t+m \bar{\varepsilon}_{n}^{f}$,

from which a simple solution can be found, i.e.

$$
\begin{aligned}
\bar{\varepsilon}_{n}^{f} & =m^{n} \bar{\varepsilon}_{0}^{f}-q\left(1+m+m^{2}+\ldots+m^{n-1}\right) \Delta t \\
& =m^{n} \bar{\varepsilon}_{0}^{f}-q \frac{\left(1-m^{n}\right)}{(1-m)} \Delta t .
\end{aligned}
$$

Since $m<1$ the asymptotic solution for large $n$ is readily obtained as

$\bar{\varepsilon}_{\infty}^{f} \rightarrow-\frac{q}{1-m} \Delta t$,

and the mean observation-minus-forecast residuals $(O m F)$ converges to

$(\overline{O m F})_{\infty} \rightarrow \frac{q}{1-m} \Delta t$.

Note that the bias in the initial conditions $\left(\bar{\varepsilon}_{0}^{f}\right)$ is eliminated as $n$ becomes large (see Eq. 12). There are associated time scales in Eqs. (13) and (14) that are important to consider for the interpretation of this result. In this derivation, the time scale is tied to the assimilation cycle, but more precisely to the revisit time of the satellite over the same region so that, in effect, a reduction of variance is accounted for with $m$ or (I-KH). For ENVISAT, the revisit time is $\Delta t=12 \mathrm{~h}$ and the production rate $q$ should thus be measured with respect to this time scale. For example, suppose that the production rate $q$ is slow, taking say 30 days to double the initial concentration $x_{0}$, i.e. $q \approx x_{0} /(60 \Delta t)$. On the other hand, it is often the case that the observation error variance and the forecast error variance are not that different in value so that $1-m \approx 1 / 2$. In this case, we obtain from Eq. (14), $\overline{O m F} \approx x_{0} / 30$.The model bias and the mean observation-minus-forecast residual are, with this simple calculation, of the order of $3 \%$, whereas observation and forecast error standard deviation are usually somewhat larger, typically 10-20\%. The mean observationminus-forecast residual is in this case smaller than the standard deviation of the $O m F$ and successful assimilation is expected despite large initial biases. At the other extreme, where the production rate is fast, say on the order of a day, we have $\overline{O m F} \approx x_{0}$, and the mean $O m F(\sim 100 \%)$ then far exceeds its standard deviation likely leading to unsuccessful assimilation. Although the full analysis would entail the computation of $(\mathrm{I}-\mathrm{KH})$ which is beyond the scope of this paper, this simple analysis is nevertheless useful in providing a qualitative interpretation and a deeper understanding of the results presented in the following sections.

\section{Description of methods and diagnostics}

We define here two kinds of observation-minus-co-located forecast $(O m F)$ differences: (1) offline (or "passive") where the chemical observations are not used to initialize the model 
forecasts, and (2) online (or "active") where, through the use of an assimilation system, the observations are ingested and serve to initialize the short-term forecasts. $O m F$ in the latter differences are also referred to as innovations (Daley, 1991).

In the offline mode, excess concentrations of constituents due to EPP effects can be isolated by taking the differences between chemical observations and co-located chemical forecasts driven by assimilated temperature and wind measurements. Taking these differences $(O m F)$ actually filters out the effects of transport, gas phase chemistry, diurnal, seasonal, annual and semi-annual cycles which are generally well reproduced by our model, and thus allows isolation of the chemical anomalies caused by EPP. Furthermore, since EPP produces strong excesses of chemical constituents of the $\mathrm{NO}_{\mathrm{y}}$ and $\mathrm{HO}_{\mathrm{x}}$ families (e.g. $\mathrm{NO}_{2}, \mathrm{HNO}_{3}$, $\mathrm{OH}, \mathrm{HO}_{2}$, etc.) which are not represented in our model, the observation-minus-forecast differences (i.e., the $O m F$ s) have magnitudes well above the observation errors or chemical transport modeling uncertainties, and thus truly represent EPP effects. Tracking the daily zonal mean and standard deviation of $O m F$ as a function of time and height provides a powerful diagnostic and analysis tool of the EPP effects - a novel approach used in this study.

On the other hand, the impact of assimilating observations is generally seen through a reduction of the mean and standard deviations of the $O m F$ from offline to online. For instance, in situations where the initial conditions are grossly in error but the model has no bias, very large mean offline $\mathrm{OmF}$ are to be expected. The $O m F$ can likewise be reduced significantly from offline to online only if the model bias growth rate time scale is much longer than the observation revisit time. However, if the growth rate time scale is comparable to the observations revisit time scale, a significant reduction of the $O m F$ from offline to online cannot be achieved, as was argued in Sect. 2.4. The behavior of $O m F$ s from offline to online thus turns out to be a useful diagnostic for the presence and time scale of the model biases. It also reflects the quality of the assimilation process. For example, large mean values of passive $\mathrm{OmF}$ biases (i.e., without chemical assimilation) caused by EPP which are eliminated in the active $O m F$ (i.e., with chemical assimilation) denote either: (1) errors in the initial conditions or (2) systematic model bias linked to slow time scale (a few weeks to a few months) chemical processes. In our study, these errors mostly originate due to the absence of proper EPP modeling. Fast time scale errors will not be corrected by assimilation as discussed in Sect. 2.4. Note that intermittent physical phenomena such as EPP impacts can produce large $O m F \mathrm{~s}$ at various time scales (Sinnhuber et al., 2006; Turunen et al., 2009).

Based on the concepts discussed above, we present in Sect. 4 a new diagnostic tool which consists of pressure-time cross sections plots (pressure as vertical coordinate versus time) of means and standard deviations of passive (without chemical assimilation) versus active (with chemical assimilation) $\mathrm{OmFs}$ for long-lived species such as $\mathrm{NO}_{2}, \mathrm{HNO}_{3}, \mathrm{O}_{3}$ and $\mathrm{CH}_{4}$. Daily zonal averages are computed to eliminate the diurnal cycle dependence in order to simplify the analysis. Individual cross sections utilize approximately $12-14$ vertical bins (between 0.1 and $100 \mathrm{hPa}$ ) centered at the tangent MIPAS observations. For both passive and active cases, meteorological assimilation was performed in the GEM-BACH model using conventional data (aircraft, radiosondes, etc) as well as satellite data from the TOVS/AMSU-A instrument covering the troposphere and stratosphere. Only MIPAS temperatures were assimilated above $70 \mathrm{hPa}$ (i.e., no AMSU-A), as this was found to give the best results for temperature, ozone and $\mathrm{HNO}_{3}$ (M2007; de Grandpré et al., 2009). It is of paramount importance that the meteorology be assimilated in the same way in both cases mentioned above to ensure the close similarity of temperatures and transport in all experiments. With the help of the new tool described above, we perform the calculation of polar ozone loss based on "targeted partial column", for two different events: (1) an EPPIE which took place in a rather continuous fashion during the austral winter of 2003 (May-September 2003) and (2) a major SPE ("Halloween" storm) which occurred towards the end of October 2003 and severely impacted the mesosphere and upper stratosphere in the following weeks.

\section{Results}

\subsection{The relation between $\mathrm{NO}_{2}$ and $\mathrm{CH}_{4}$}

A scatter plot of $\mathrm{NO}_{\mathrm{x}}$ against $\mathrm{CH}_{4}$ from HALOE observations has been examined in the past to track the signature of EPP-IE. The deviation from a linear relationship in the scatter plot of $\mathrm{NO}_{\mathrm{x}}$ against $\mathrm{CH}_{4}$ (high $\mathrm{NO}_{\mathrm{x}}$ and low $\mathrm{CH}_{4}$ ) indicates an EPP-IE (Siskind et al., 2000; Randall et al., 2006). In Fig. 1a (case without chemical assimilation) and Fig. $1 \mathrm{~b}$ (case with assimilation), $\mathrm{NO}_{2}$ is plotted against $\mathrm{CH}_{4}$ for both MIPAS observations ${ }^{3}$ and the model output near $2 \mathrm{hPa}$ for the second half of August 2003 in the Southern Hemisphere $\left(30^{\circ} \mathrm{S}-90^{\circ} \mathrm{S}\right)$. These diagrams illustrate different modes (labeled 1, 2 and 3) which characterize different dynamical and photochemical conditions occurring in the stratopause/upper stratosphere region. The day mode (1) is due to the photo-dissociation of $\mathrm{NO}_{2}$, which reduces its mixing ratios to very low values irrespectively of $\mathrm{CH}_{4}$. For the second mode (2), low (high) values of $\mathrm{CH}_{4}$ near $2 \mathrm{hPa}$ correspond to low (high) values of $\mathrm{NO}_{2}$ since the source of both constituents is normally located in the troposphere. In this particular case, species are well correlated and this explains the tendency to obey a straight line relationship in the species scatter diagram. For the third mode (3), low values of methane correspond to high values of $\mathrm{NO}_{2}$, which

\footnotetext{
${ }^{2}$ This layer is identified using passive $O m F$ biases (see Sect. 4).

${ }^{3}$ MIPAS/ESA observations do not include $\mathrm{NO}_{\mathrm{x}}\left(\mathrm{NO}_{2}+\mathrm{NO}\right)$ but only $\mathrm{NO}_{2}$ which is nevertheless a good proxy for $\mathrm{NO}_{x}$ during the austral winter.
} 
strongly suggests the presence of a mesospheric source of nitrogen which is transported downward within the polar vortex. Such a phenomenon is seen in the MIPAS dataset as shown in Fig. 1 and refers to the EPP-IE signature (Randall et al., 2006, 2007). When chemical assimilation is turned on (Fig. 1b), the third mode (3) is now present in both the observations and the model, which confirms that the phenomenon is well captured by our data assimilation system and our resulting chemical analyses. Therefore, Fig. 1 and other similar scatter diagrams are not only useful in identifying EPP phenomena but turn out to be a tool to validate the consistency of the model and the assimilation scheme.

\subsection{Analysis of an EPP-IE case in 2003 using $\mathrm{OmF}$ diagnostics}

In this section and those which follow, we examine the spatio-temporal distribution of polar $O m F$ s. Results are first presented for the period 18 August (Julian day 230) to 5 December 2003 (Julian day 340) for the South Pole region $\left(60^{\circ} \mathrm{S}-90^{\circ} \mathrm{S}\right)$. The Northern Hemisphere is not examined in this section since the EPP-IE influence is smaller in this region due to numerous factors including the inter-hemispheric asymmetry of the solar zenith angle, seasonal differences and different offsets of geomagnetic and geographic poles (Jackman et al., 2008) as well as a typical stronger planetary wave regime. In Fig. 2 (top panels) the passive $O m F$ plots (without chemical assimilation) show massive downward transport of $\mathrm{NO}_{2}$ anomalies from the lower mesosphere to the middle stratosphere region. Note that the end of the polar night is approximately indicated by a dashed vertical white line in the figures. We have selected 12 September (day 255) as the end of the polar night since beyond this date most of the area beyond $60^{\circ} \mathrm{S}$ is partially illuminated over the $24 \mathrm{~h}$ period. This date helps to illustrate the period at which the photochemistry starts to have a significant impact on the mean O-P value in the region. This choice has been drawn on the various panels in order to facilitate the discussion.

The rate of descent of the anomalies in the stratosphere is approximately depicted by the slope of the black dashed line which represents the location of the mean $O m F$ local maximum throughout the period for $\mathrm{NO}_{2}$. Figure $2 \mathrm{a}$ also shows that $O m F$ is changing sign near the stratopause (around 0.7$1 \mathrm{hPa}$ ) right after the end of the polar night, suggesting a photochemical dependence on the model bias since here $\mathrm{OmF}$ varies with the solar zenith angle. More interestingly, important $\mathrm{OmF}$ anomalies persist at lower altitudes (around and below $10 \mathrm{hPa}$ along the slanted dashed line) until about Julian day 295 (end of October) where the polar vortex starts to break up thus eliminating the trace of EPP- $\mathrm{NO}_{\mathrm{x}}$ through mixing processes. Anomalies descending into the middle stratosphere survive longer after the end of the polar night due to the fact that $\mathrm{NO}_{\mathrm{x}}$ photolysis decreases rapidly below the stratopause, which allows the $O m F$ excesses of $\mathrm{NO}_{2}$ to reach lower levels. The similar descent in the time series
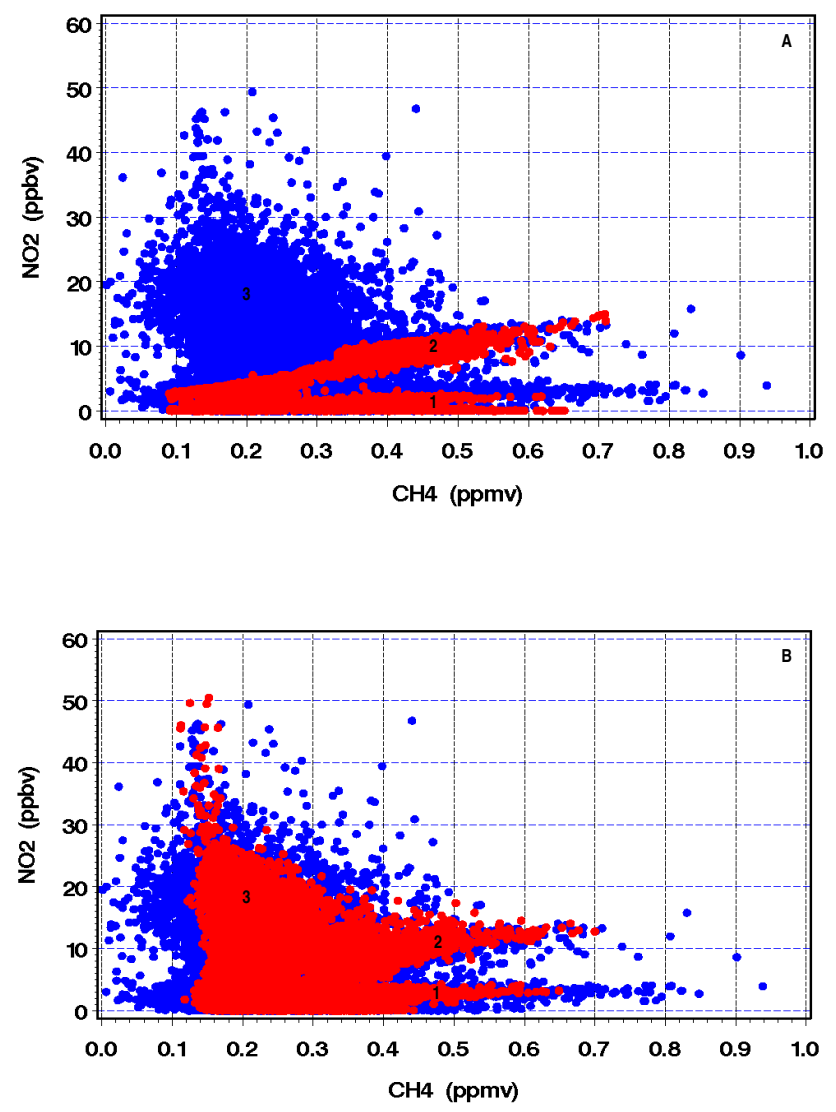

Fig. 1. Scatter diagram of $\mathrm{NO}_{2}$ versus $\mathrm{CH}_{4}$ for the Southern Hemisphere $\left(30^{\circ} \mathrm{S}-90^{\circ} \mathrm{S}\right)$ around $2 \mathrm{hPa}$ for MIPAS observations (blue) and model outputs (red): (A) without chemical assimilation, (B) with chemical assimilation, 1: day mode, 2: nocturnal mode, 3: EPP signature.

of $\mathrm{OmF}$ standard deviation (Fig. 2b) is another indication of the strength of the EPP-IE signal in the $\mathrm{NO}_{2}$ measurements. Note that the slanted dashed line representing the location of the maximum of the passive mean $O m F$ in Fig. 2a has been superimposed on Fig. $2 b$ for comparison purposes. It indicates that anomalies of the standard deviation of passive $O m F$ follow a very close pattern of that of mean $O m F$. With chemical assimilation, the descending tongue of $\mathrm{OmF}$ almost vanishes (Fig. 2c) and the standard deviation (Fig. 2d) is reduced, particularly along the dashed line which confirms that our assimilation of MIPAS $\mathrm{NO}_{2}$ measurements successfully incorporates the missing sources of nitrogen during EPP events. The large reduction for the biases and standard deviations following the assimilation of $\mathrm{NO}_{2}$ (bottom panels) demonstrates the capability of the assimilation system to capture the slow time scale errors (lifetime of a few weeks to a few months) and/or to correct improper initial conditions. However, $O m F$ anomalies (for example caused by artefacts linked to the sponge layer) are still apparent near the model top (Fig. 2c and d), which indicates that the assimilation 

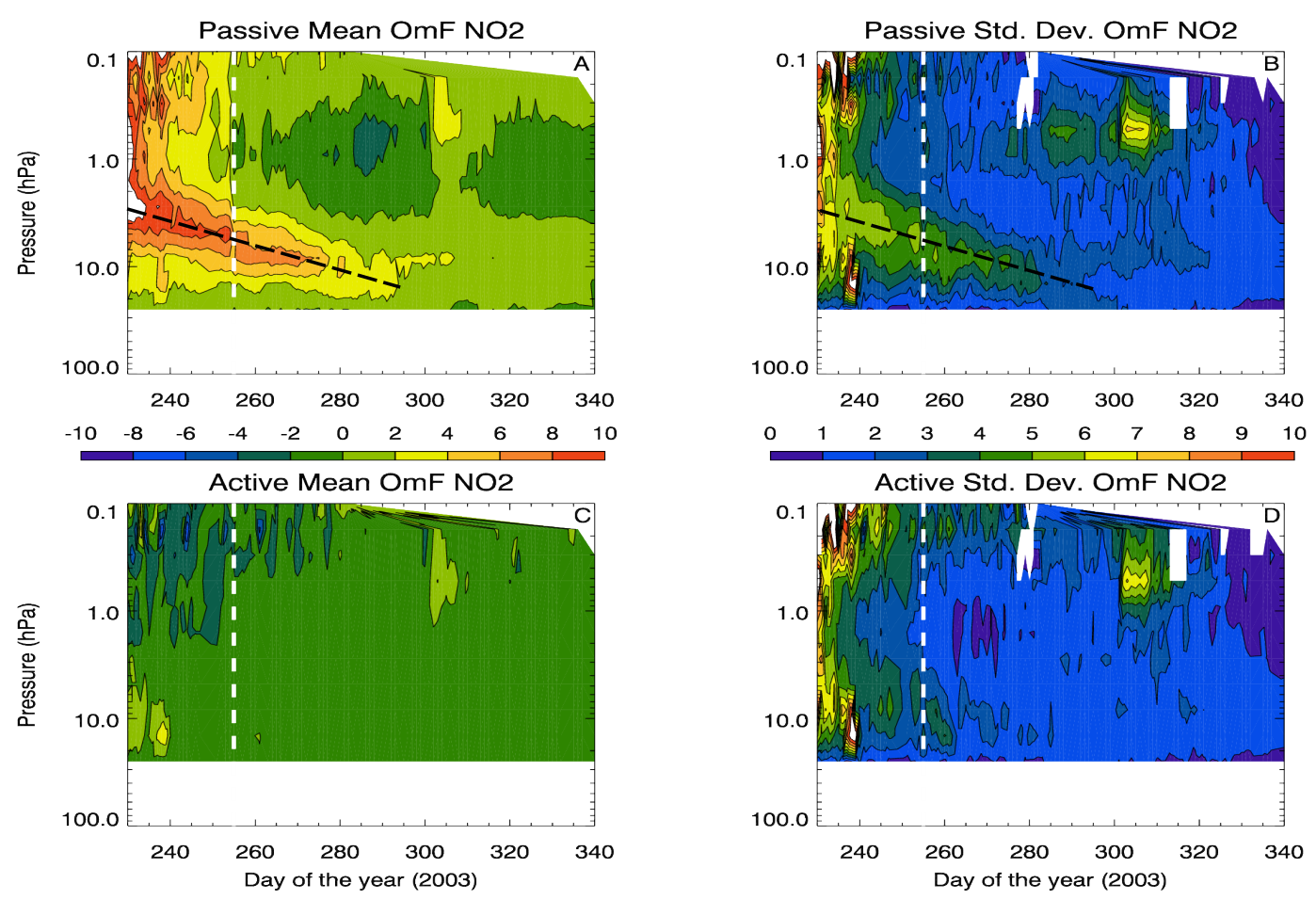

Fig. 2. Pressure-time plots of $\mathrm{NO}_{2} \mathrm{OmF}$ in ppbv. Top panels: no chemical assimilation, (A) mean, (B) std. dev. Bottom panels: (C) and (D) are identical to (A) and (B) respectively but with chemical assimilation included. The domain is the South Pole region (latitudes $>60^{\circ} \mathrm{S}$ ) during 2003. The vertical dashed white line roughly indicates the end of the polar night and the slanted black dashed line, the rate of descent for the local maximum of mean $O m F$. Note that no MIPAS-ESA retrievals are available for $\mathrm{NO}_{2}$ below about $25 \mathrm{hPa}$.

system cannot eliminate those types of fast time scale systematic errors, as explained in Sect. 3. For $\mathrm{HNO}_{3}$ (Fig. 3), some of the findings noted above apply as seen below. The trace of the EPP effects in the middle stratosphere is clear and approximately (with a slight vertical displacement) follows the descent rate found for $O m F \mathrm{NO}_{2}$ anomalies below $1 \mathrm{hPa}$ (depicted by the black dashed line superimposed from Fig. 2a). A new feature appears in the particular case of $\mathrm{HNO}_{3}$, e.g. the $O m F$ signal peaks around $30 \mathrm{hPa}$ and becomes very significant towards the end of the polar night (ending around Julian day 255). The latter is attributed to the misrepresentation of denitrification and sedimentation in the model. Note that with MIPAS assimilation, the bias associated with this misrepresentation disappears (Fig. 3c). This effect is also present in other years of simulation (i.e., 2007 and 2008) which are non-EPP years (results not shown). No other major biases are known for the GEM-BACH model for $\mathrm{HNO}_{3}$ in the absence of EPP phenomena (see M2007 for more details and Batchelor et al., 2009). For $\mathrm{HNO}_{3}$, the large mean and standard deviation associated with EPP are eliminated and strongly reduced, respectively, by assimilation (bottom panels of Fig. 3). The success of assimilation for $\mathrm{HNO}_{3}$ suggests that the $O m F$ anomalies were not controlled by fast time scales model errors.
We now examine $O m F$ plots for ozone (Fig. 4). First, note that the small ozone model deficit (positive $O m F$ of $\sim 0.2$ $0.4 \mathrm{ppmv}$ ) which cannot be eliminated after assimilation in the upper stratosphere and stratopause regions (Fig. 4c, after day 270 near $1 \mathrm{hPa}$ ) is attributed to an inaccurate photochemistry (fast time scales errors, i.e. $\sim 1$ day or less). The slanted dashed line corresponding to the case of $\mathrm{NO}_{2}$ (see on Fig. 2a and $b$ ) has also been superimposed on Fig. $4 a$ and $b$ in order to establish some connections: as $\mathrm{HNO}_{3}$ and $\mathrm{NO}_{2} \mathrm{OmF}$ diminish along this line (as shown in Figs. 2a and 3a), ozone $O m F$ s (Fig. 4a) slowly change sign after the end of the polar night and then gradually intensify (in absolute value) until the last week of October ( day 300). This suggests a link between $\mathrm{NO}_{2}, \mathrm{HNO}_{3}$ anomalies and polar ozone loss (see also Sect. 4.4 for more details). By the time the $\mathrm{NO}_{2} \mathrm{OmF}$ biases have been reduced to background levels (around Julian day 295, Fig. 2a), significant negative ozone $O m F$ biases develop (Fig. 4a near $10 \mathrm{hPa}$ ). This indicates that the chemical origin of the negative ozone bias is from EPP-NO $\mathrm{NO}_{\mathrm{x}}$. During the same period, the $\mathrm{HNO}_{3} \mathrm{OmF}$ biases (Fig. 3a) slowly decrease (although not as quickly as for $\mathrm{NO}_{2}$ ) which also coincides with the build-up of negative ozone $O m F$ biases. The region near $10 \mathrm{hPa}$ around Julian day 285 to 295 corresponds to the maximum depletion of ozone mixing ratio (see also Fig. 10). It is clear that there is a change of regime 

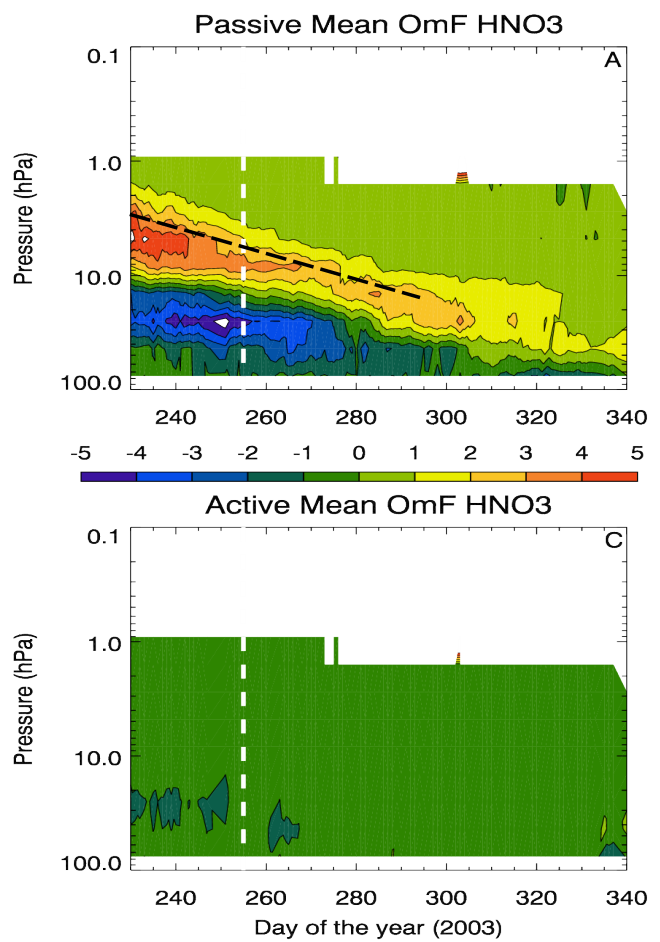
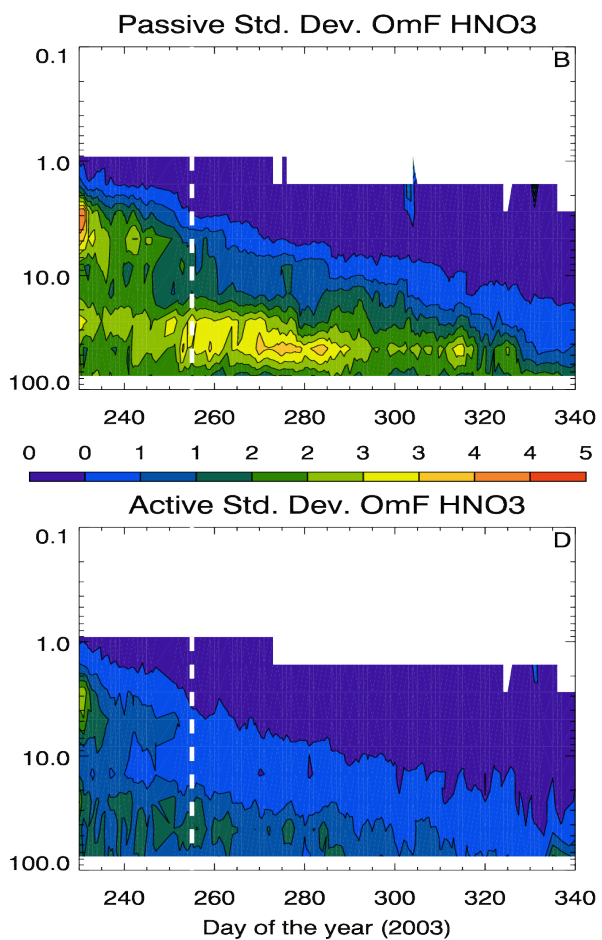

Fig. 3. As Fig. 2 but for $\mathrm{HNO}_{3}$ : Top (without assimilation), bottom (with assimilation), left (mean), right (std. dev.). The rate of descent of mean $\mathrm{NO}_{2} \mathrm{OmF}$ (black dashed line) is superimposed for comparison. No MIPAS-ESA retrievals are available for $\mathrm{HNO}_{3}$ in the mesosphere (above roughly $1 \mathrm{hPa}$ ).

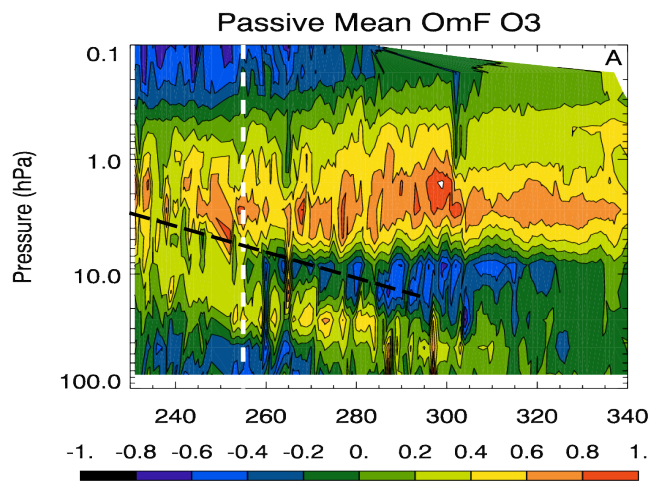

Active Mean OmF O3

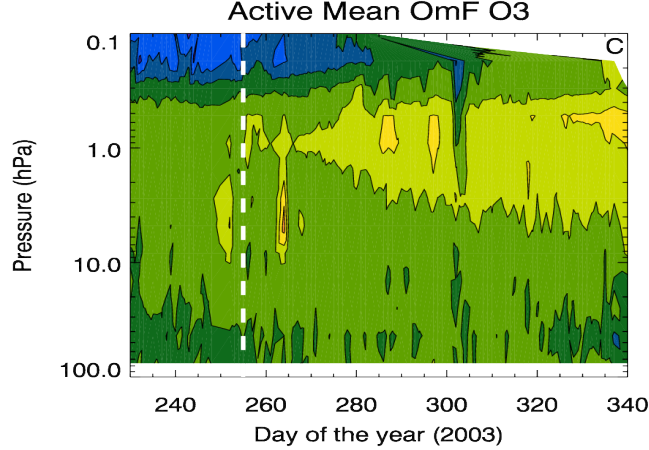

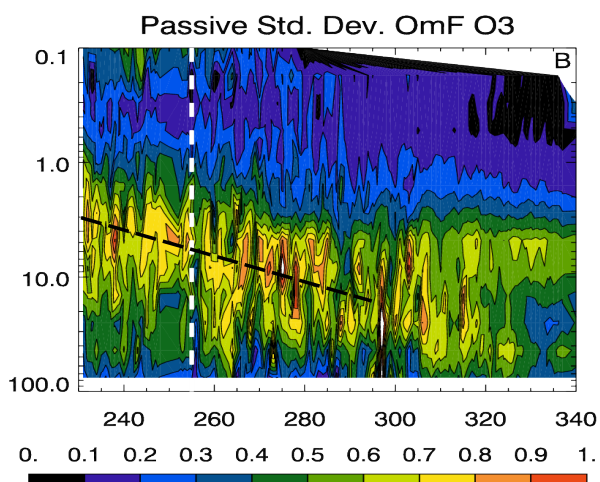

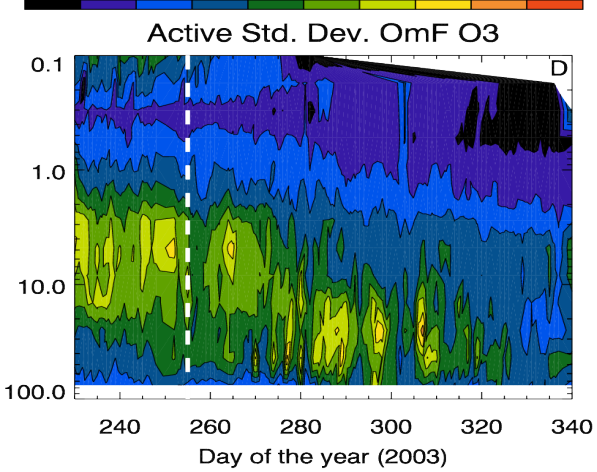

Fig. 4. As Fig. 2 but for $\mathrm{O}_{3}$ (units are ppmv). 

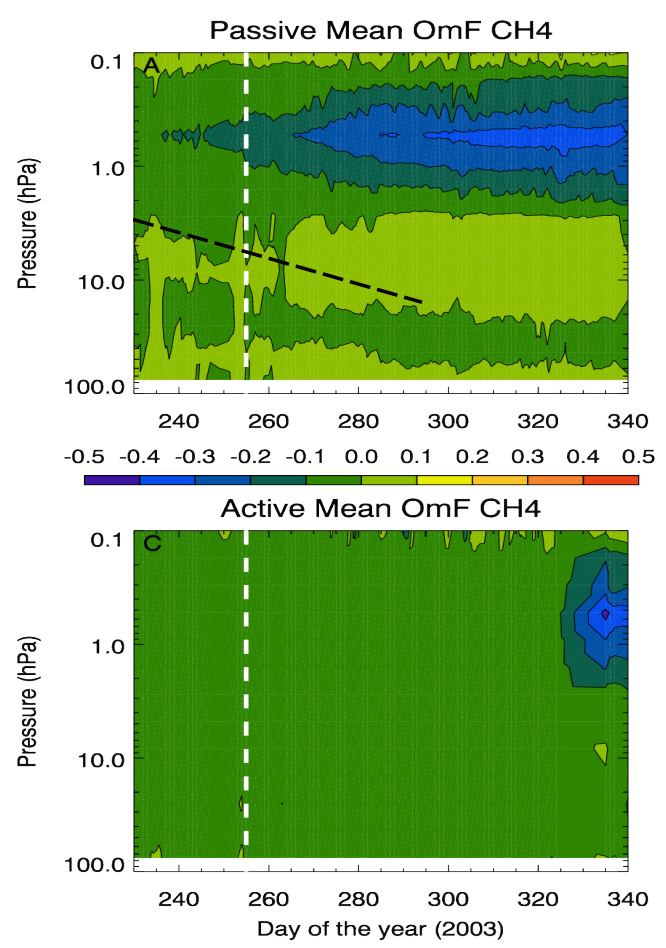

Fig. 5. As Fig. 2 but for $\mathrm{CH}_{4}$ (units are ppmv).

for the chemical constituent anomalies before and after the end of the polar night, which is seen more strongly for ozone and which is attributed to changes in the lifetime of $\mathrm{NO}_{\mathrm{y}}$ and $\mathrm{HO}_{\mathrm{x}}$ families from darkness to sunlit conditions. These diagrams suggest that the excesses of $\mathrm{NO}_{\mathrm{y}}$ are partly converted into NO which contributes to ozone depletion through catalytic reactions when the sun reappears in the polar vortex (see Reactions R1 and R2, Appendix A). Figures 2 and 3 also allow the calculation of the e-folding times of $O m F \mathrm{NO}_{2}$ and $\mathrm{HNO}_{3}$, throughout the descent, which also turn out to be the lifetimes of the $\mathrm{HNO}_{3}$ and $\mathrm{NO}_{2}$ constituents themselves in this particular situation. Regression analyses using the following expressions have been conducted to fit $\mathrm{OmF}$ data to the following curves:

$\operatorname{OmF}\left(\mathrm{NO}_{2}\right)(t)=\operatorname{OmF}\left(\mathrm{NO}_{2}\right)\left(t_{o}\right) \exp \left(-c_{1}\left(t-t_{o}\right)\right)$

$O m F\left(\mathrm{HNO}_{3}\right)(t)=O m F\left(\mathrm{HNO}_{3}\right)\left(t_{o}\right) \exp \left(-c_{2}\left(t-t_{o}\right)\right)$

where $O m F\left(\mathrm{NO}_{2}\right)(t)$ denotes the local maximum passive mean $O m F$ for $\mathrm{NO}_{2}$ at time $t, t_{o}$ is the starting time expressed in Julian day (e.g. day 230) and $c_{1}, c_{2}$, the rates of decrease of the $\mathrm{NO}_{2}$ and $\mathrm{HNO}_{3} O m F$ anomalies with time. We obtained $c_{1}=0.0183\left(R^{2}=0.83, p<0.01\right)$ and $c_{2}=0.0123$ $\left(R^{2}=0.85, p<0.01\right)$. The $1 / c_{1}$ e-folding times are about 55 days for the $\mathrm{NO}_{2} O m F$ and about 80 days for the $\mathrm{HNO}_{3}$ $\mathrm{OmF}$, respectively. Those figures are comparable but nevertheless significantly higher than a similar evaluation made by

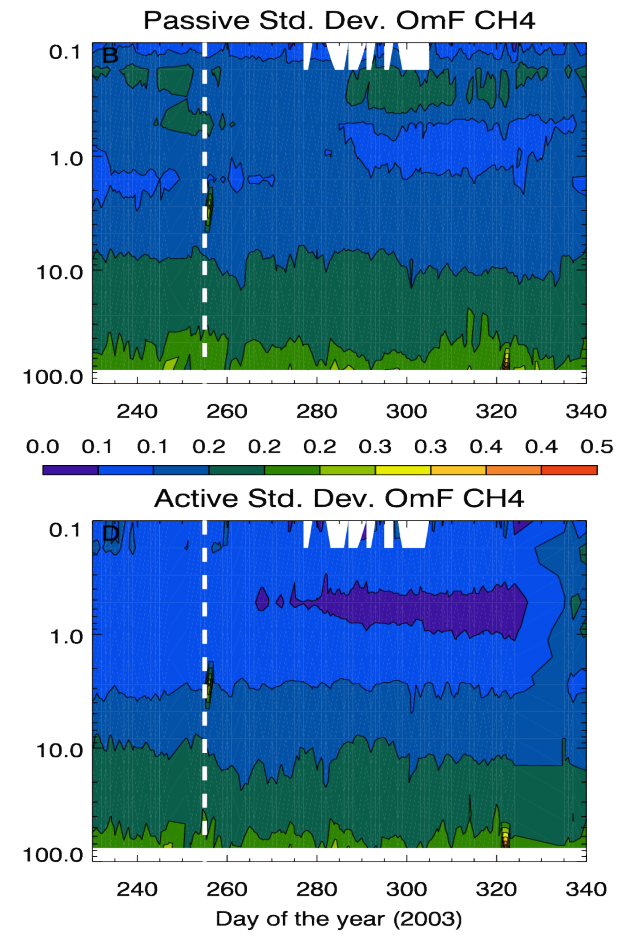

Rinsland et al. (2005) but at higher altitude and for $\mathrm{NO}_{\mathrm{x}}$ during February-March 2004 using ACE observations. In any cases, computed time scales involved here are slow, supporting the connection with a successful chemical assimilation and a significant reduction of $O m F$ anomalies as shown in Figs. 2 through 4 (bottom panels) and predicted in Sects. 2.4 and 3. From Fig. 4a (and also Fig. 10) it is interesting to observe that it is also after about 55 days following $t_{o}$ (i.e., Julian day 285) that ozone depletion becomes maximum (i.e., $\mathrm{OmF}$ reaches a minimum) which is consistent with the above results.

The presence of an anomalous layer for $\mathrm{HNO}_{3}$ in the upper stratosphere descending and persisting with time into the middle stratosphere has been explained in terms of hydrated ion cluster chemistry (see Reactions R9 and R10, Appendix A) in the upper stratosphere following EPP events (Kawa et al., 1995; de Zafra and Smyshlyaev, 2001; LopezPuertas et al., 2005; Orsolini et al., 2005; Stiller et al., 2005; Jackman et al., 2008). Note that Fig. 3a is consistent with the pressure-time cross section for MIPAS $\mathrm{HNO}_{3}$ as presented by Stiller et al. (2005) (their Fig. 1 after 11 August and for potential temperature smaller than $1800^{\circ} \mathrm{K}$ ). It is also consistent with $\mathrm{ODIN} \mathrm{HNO}_{3}$ measurements (figure not shown).

Figure 5 shows the $O m F$ diagnosis plots for methane $\left(\mathrm{CH}_{4}\right)$. This constituent is considered as a good dynamical tracer which can be used to diagnose the transport characteristic of the model and its assimilation system. Small values of the passive $O m F$ mean and standard deviation (Fig. 5a) along 
the slanted dashed line (superimposed from Fig. 2a) indicate that no significant dynamic problem is present in the model bias in the middle stratosphere where we have focused our attention so far and where the ozone loss and EPP-IE signature of $\mathrm{NO}_{\mathrm{y}}$ occurs. This means that the biases shown above are mostly of chemical nature and not driven by the dynamics. Note that near the stratopause and in the lower stratosphere important $\mathrm{O}$ and $\mathrm{F}$ mismatches for methane (Fig. 5a) are mainly attributed to imprecise initial conditions or model top artefacts. In any cases, the $\mathrm{CH}_{4}$ assimilation of MIPAS observations generally significantly improves the results for the systematic biases in the whole domain (Fig. 5c).

\subsection{SPE case during boreal winter 2003}

Several solar eruptions occurred in October-November 2003 producing an enormous amount of high energy particles which penetrated in the polar atmosphere. One eruption at the end of October 2003, the so-called "Hallowe'en storm" is considered to be the fourth largest in the past half century or so with computed $\mathrm{NO}_{\mathrm{y}}$ production in the middle atmosphere of 5.6 Gigamoles (Jackman et al., 2008). This solar flare has led to an extreme distortion of the Van Allen belts (Baker et al., 2004) and left in its wake several geomagnetic storms from mid-November to mid-December producing several episodes of relativistic electron precipitation and auroras (Turunen et al., 2009). Figure 6 reproduces the proton flux data from GOES-11 (http:/www.spwc.noaa.gov) shortly before and after the SPE which maximum peak took place around Julian day 302-303 (29-30 October). It is therefore anticipated that the "Hallowe'en storm" should leave a strong signature in the upper atmosphere with solar proton flux increases to 4 or 5 orders of magnitude above the background (for protons having energy $E>10 \mathrm{MeV}$ ). Note that protons with $E>30 \mathrm{MeV}$ have sufficient energy to reach the stratosphere and produce $\mathrm{NO}_{\mathrm{x}} / \mathrm{HO}_{\mathrm{x}}$ directly in this region (Turunen et al., 2009) which can catalytically destroy ozone (see Reactions R1-R4, Appendix A).

Figures 7 through 9 provide the $O m F$ plots for $\mathrm{NO}_{2}$, $\mathrm{HNO}_{3}$ and $\mathrm{O}_{3}$ respectively with and without assimilation, for periods before and after the onset of the storm (the day just before the maximum intensity of the storm was felt in the stratosphere is indicated by a dashed white vertical line, i.e., 28 October or day 301). We now focus on the North Pole $\left(60^{\circ} \mathrm{N}-90^{\circ} \mathrm{N}\right)$ since the South Pole region had experienced only little trace of the SP event of October/November 2003 (Funke et al., 2005; see also Figs. 2 and 3, Sect. 4.2). Immediately after the onset of the "Hallowe'en storm", passive $\mathrm{OmF}$ means for $\mathrm{NO}_{2}$ largely exceeding (by at least 2 orders of magnitude) the background values start appearing in the upper domain (Fig. 7a and b). These excesses subsided from the mesosphere into the upper stratosphere and even reached the middle stratosphere by the end of the period. With chemical assimilation, $\mathrm{NO}_{2}$ biases (Fig. 7c) diminish significantly showing the beneficial impact of assimilation on the short

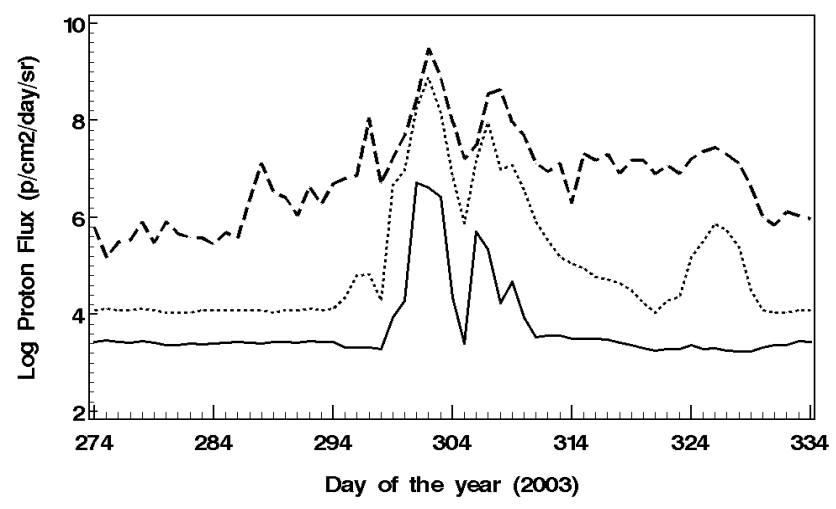

Fig. 6. Solar proton flux measurements by GOES-11 (OctoberNovember 2003) for protons having energy >1 MeV (black dashed), $10 \mathrm{MeV}$ (thin dashed) and $100 \mathrm{MeV}$ (solid black). The unit for flux is protons $/ \mathrm{cm}^{2} /$ day/steradian (source of data: http: //www.spwc.noaa.gov).

term forecast. The standard deviations are also slightly reduced for $\mathrm{NO}_{2}$ with assimilation (Fig. 7d) especially along the slanted dashed line. This line represents the rate of descent of the $\mathrm{NO}_{2} \mathrm{OmF}$ anomalies within the polar vortex which can now be used as a proxy for atmospheric subsidence in the region. It is thus evaluated at about $11 \mathrm{~km}$ per month which results in a significant downward transport of the chemical perturbation following the event. This value is higher but in the same range as found by other authors (Manney et al., 1994; Rinsland, 2005) under similar conditions. Using the same methodology as in the previous section, a least square fit to the following expression:

$O m F\left(\mathrm{NO}_{2}\right)(t)=O m F\left(\mathrm{NO}_{2}\right)\left(t_{o}\right) \exp \left(-c_{3}\left(t-t_{o}\right)\right)$

gives $c_{3}=0.0315$ with $R^{2}=0.82(p<0.01)$. The e-folding time $1 / c_{3} \sim 30$ days is about two times smaller here than for the EPP-IE case (Sect. 5.2) but is now in agreement with the results of Risland et al. (2005) obtained for $\mathrm{NO}_{\mathrm{x}}$. The shorter time scale obtained for $\mathrm{NO}_{2}$ as compared to the EPP-IE case is due to the location of the maximum $O m F$ biases now at a higher altitude where the lifetime of $\mathrm{NO}_{2}$ is smaller (Brasseur and Solomon, 2005). $\mathrm{OmF}$ for $\mathrm{HNO}_{3}$ (Fig. 8a and b) show significant excesses in the $1-2 \mathrm{hPa}$ layer (labeled as 1) and appearing right after the onset of SPE. Note that there were no MIPAS-ESA retrievals available above $1 \mathrm{hPa}$ to be assimilated for $\mathrm{HNO}_{3}$. It is very likely that this excess in $\mathrm{HNO}_{3} \mathrm{OmF}$ in the stratopause/upper stratosphere region is the signature of fast gas phase chemistry (Reactions R6-R8, Appendix A) and/or ion recombination chemistry (Reaction R5 in Appendix A) following the production of $\mathrm{NO}_{\mathrm{x}}$ and $\mathrm{HO}_{\mathrm{x}}$ during EPP (Brasseur and Solomon, 2005; Lopez-Puertas et al., 2005; Jackman et al., 2008; Verronen et al., 2008). Although the gas phase reactions R6-R8 are included in our model, the lack of assimilation of $\mathrm{HO}_{\mathrm{x}}$ and $\mathrm{NO}$ produces the $\mathrm{HNO}_{3} \mathrm{OmF}$ trace which appears near 

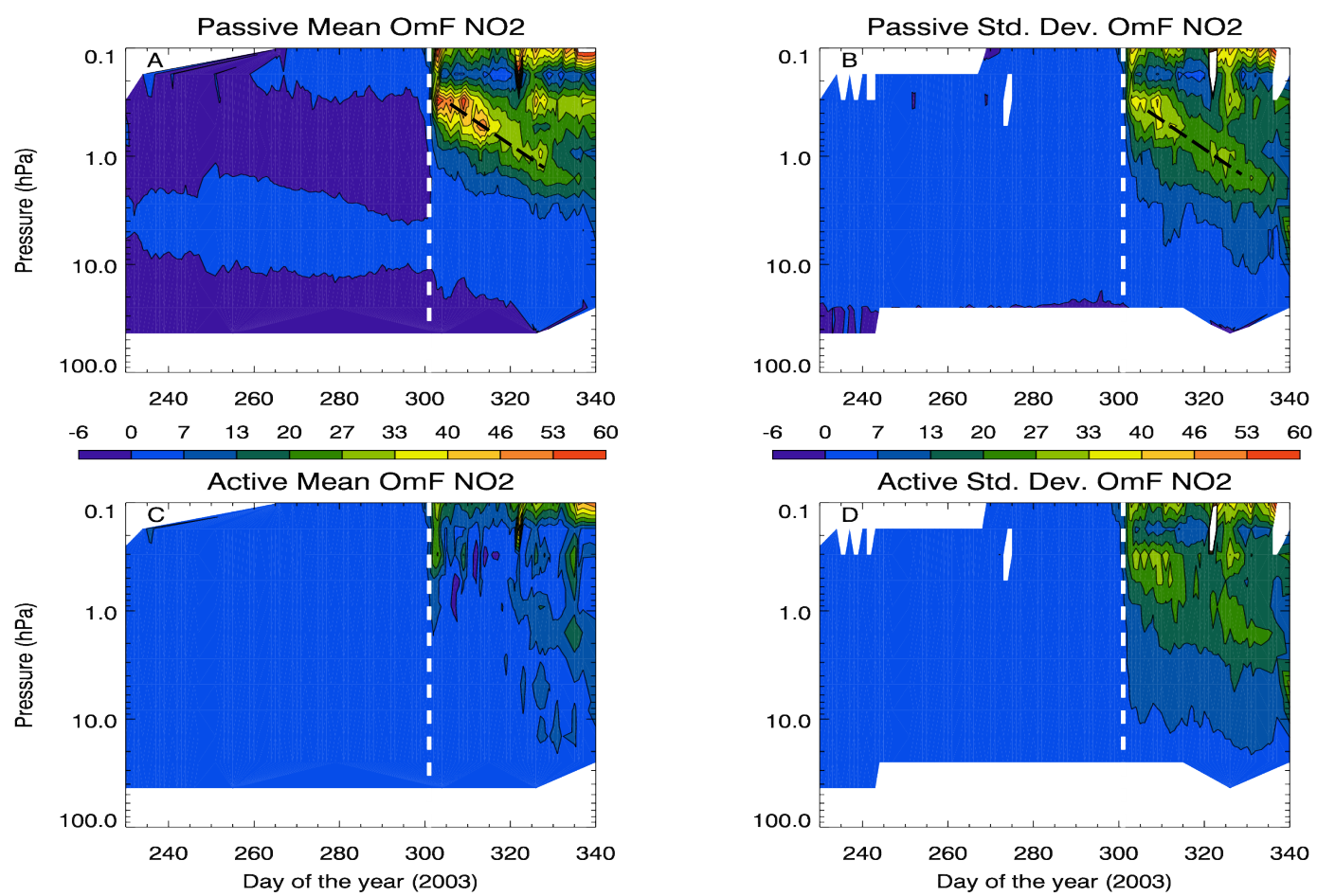

Fig. 7. Pressure-time plots of $\mathrm{NO}_{2} \mathrm{OmF}$ in ppbv for the SPE case (Hallowe'en storm). Top panels: no chemical assimilation, (A) mean, (B) std. dev. Bottom panels: (C) and (D) are identical to (A) and (B) respectively but with chemical assimilation included. The domain is the North Pole (lat $>60^{\circ} \mathrm{N}$ ) during 2003. The dashed vertical white line indicates the beginning of the SPE storm (28 October 2003, i.e., Julian day 301) and the black dashed line represents the rate of descent of the mean $\mathrm{OmF}$.

$1 \mathrm{hPa}$ on Fig. 8a and b. A secondary maximum of mean $\mathrm{HNO}_{3} \mathrm{OmF}$ in November (labeled as 2) appears at about $2 \mathrm{hPa}$ near Julian day 325 to 340 and is associated with the production and downward transport of $\mathrm{NO}_{\mathrm{x}}$ which reaches the $1 \mathrm{hPa}$ level about 1 month after the onset of the SPE event. During the descent in the polar vortex, active nitrogen compounds are converted into $\mathrm{HNO}_{3}$ but some controversy seems to exist about the origin of the $\mathrm{HNO}_{3}$ enhancement. Aikin (1994, 1997) and Verronen et al. (2008) claimed that the ion-ion recombination is the most important process in the upper stratosphere to explain the $\mathrm{HNO}_{3}$ enhancement following EPP. However, this process becomes less important in the middle or lower stratosphere at the expense of the ioncluster chemistry and/or heterogeneous chemistry. On the other hand, Kawa et al. (1995), McDonald et al. (2000), de Zafra and Smyshlaev (2001), Orsolini et al. (2005), Stiller et al. (2005), also analyzed $\mathrm{HNO}_{3}$ enhancement following EPP events and came to the conclusion that ion-cluster chemistry and/or heterogeneous chemistry on sulfate aerosols were the two dominant mechanisms of production in the stratosphere of enhanced $\mathrm{HNO}_{3}$ layers. In Fig. 3a, we show the $\mathrm{OmF}$ associated with $\mathrm{HNO}_{3}$. Above $10 \mathrm{hPa}$, (mostly before the polar night), the signature of this $\mathrm{HNO}_{3}$ enhanced layer appears very clearly. In figure $3 \mathrm{a}$, the enhancement is not likely to be associated to ion-ion recombination process which a fast time scale because the mean $O m F$ s vanish with assimilation (as in Fig. 3c) and this only happens in the case of slow time scale reactions (see Sects. 2.4 and 3 ). For the SPE case (see Fig. 8a), we identified 4 regions of maximum $\mathrm{HNO}_{3} \mathrm{OmF}$ (labeled 1, 2, 3 and 4 on the figure). With assimilation (bottom panels of Fig. 8), the maxima of region 3 and 4 disappear and only 1 and 2 are reduced but still hang around after assimilation. This would indicate that the former are associated with slow time scale errors whereas the latter are linked with faster time scale errors. Since ion-ion recombination is a fast time scale process, it is unlikely that this process is associated with region 3 for example. However, in regions 1 and 2 , ion-ion recombination could play a major role (as suggested in Verronen et al., 2008).

On the other hand, the e-folding time computed above ( $\sim 30$ days) matches the time scale of processes associated with the theory of ion cluster chemistry involving water for $\mathrm{NO}_{2}$ decrease in region 3 (see Stiller et al., 2005). In the lower stratosphere, relatively important model errors also exist (labeled 4 on Fig. 8a and b) with a sharp and persistent mean $\mathrm{OmF}$ maximum for $\mathrm{HNO}_{3}$ around $20-30 \mathrm{hPa}$ during the period. The latter phenomenon is not related to SPE event (since it started to build up long before day 301) and could be explained by some model deficiencies regarding $\mathrm{NO}_{\mathrm{y}}$ partitioning in the region. 

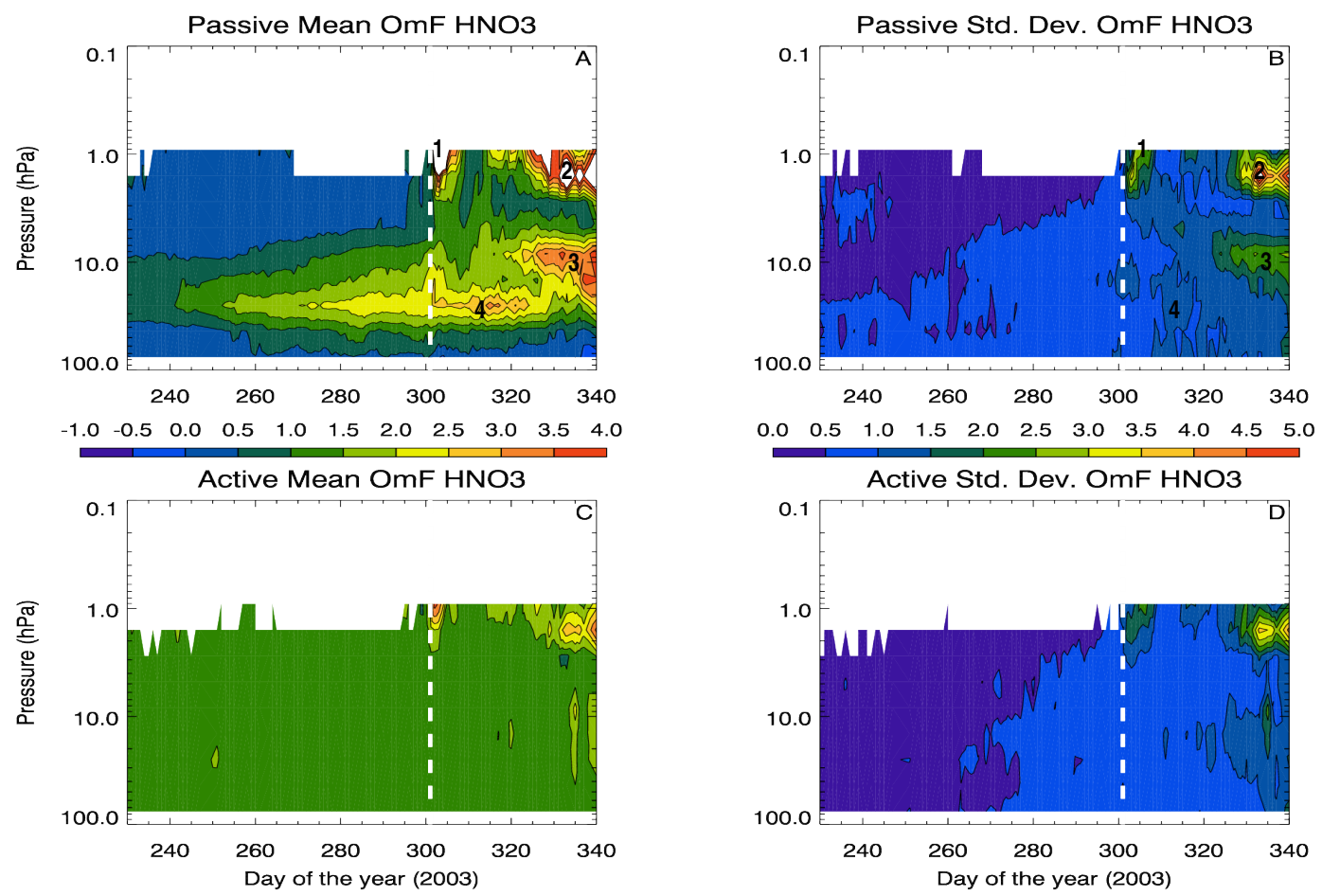

Fig. 8. As Fig. 7 but for $\mathrm{HNO}_{3}$. No data is available for $\mathrm{HNO}_{3}$ above roughly $1 \mathrm{hPa}$.

Figures 7 and 8 indicate that the nature of the errors in the stratosphere is mostly associated with initial conditions or slow time scale modeling errors (except for those near $1 \mathrm{hPa}$ ). Note that signature of SPE persisting after assimilation in the upper stratosphere and stratopause regions (labeled as 1 or 2 in top panels of Fig. 8) would indicate, in principle, fast time scale model errors. However, for the region labeled as 2, it is not possible to confirm this evaluation made with the $\mathrm{OmF}$ method since there were no data to assimilate above $1 \mathrm{hPa}$ where the air originated from. Nevertheless, Jackman et al. (2008) demonstrated that a buildup of $\mathrm{N}_{2} \mathrm{O}_{5}$ (a precursor of $\mathrm{HNO}_{3}$, see Reactions R9-R10, Appendix A) takes place in that region in their model for the same event. This seems to support the presence of hydrated ion cluster chemistry making unclear the real origin of $O m F$ in region 2. As a matter of fact, according to Verronen et al. (2008), the $\mathrm{HNO}_{3}$ enhanced layer should be due to ion/ion recombination process as discussed above.

Coincident with excesses for the $\mathrm{NO}_{\mathrm{y}}$ family in the region $1-2 \mathrm{hPa}$, a reduction of the ozone $O m F$ mean (Fig. 9a) is clearly noted after the onset of SPE with the lowest value occurring around days 325-330 (see also Fig. 11). OmF biases are about 0.2 to $0.6 \mathrm{ppmv}$ shortly before day 301 and fall to near zero following the SPE. This reduction demonstrates its sensitivity to the $\mathrm{NO}_{\mathrm{y}}$ background conditions in the region.

The positive ozone model bias which appears in the background in the lower mesosphere/upper stratosphere region $(0.5-2 \mathrm{hPa})$ throughout the whole period (but mostly before day 301) is linked to a known misrepresentation of the photochemistry (M2007) as in the case of EPP-IE in the Southern Hemisphere. Finally, at the model top, assimilation has little effect due to fast time scale errors linked with the sponge as previously noted. In summary, MIPAS-ESA data is useful for assimilation and diagnostic purposes even in periods of strong EPP effects at least in the region $30-45 \mathrm{~km}$ where impact on the on the ozone column is likely to occur at least in the cases shown in this study.

\subsection{Calculation of the polar ozone loss due to EPP based on $\mathrm{OmFs}$}

In this section, we evaluate the stratospheric partial column ozone loss for the cases studied previously in Sect. 4.2 and 4.3 with the help of the mean $O m F$ cross sections. Figure 10 shows time series of the passive $O m F$ biases for $\mathrm{O}_{3}$, $\mathrm{NO}_{2}$ and $\mathrm{HNO}_{3}$ at the $14.5 \mathrm{hPa}$ level for the EPP-IE case described in Sect. 4.2. This level was selected since it corresponds to the maximum impact of EPP (maximum absolute value of mean $\mathrm{OmF}$ biases) of ozone. During the polar night (Julian day 230-255) OmF biases for $\mathrm{NO}_{2}$ and $\mathrm{HNO}_{3}$ and ozone display a weak positive correlation whereas when the polar region is illuminated but the polar vortex still present in the lower stratosphere (day 270-315), the relationship is changed to a negative correlation (see Table 1 for details). The increase of $O m F$ biases for $\mathrm{NO}_{2}$ starting around $\mathrm{Ju}-$ lian day 270 is clearly related to the increase brought by the 

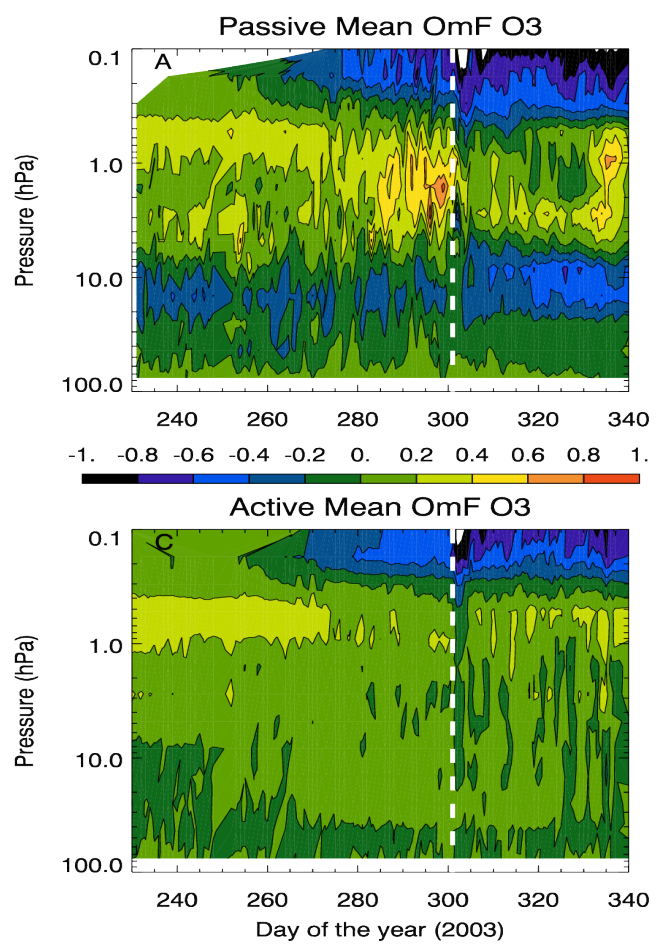

Fig. 9. As Fig. 7 but for $\mathrm{O}_{3}$ (units are ppmv).

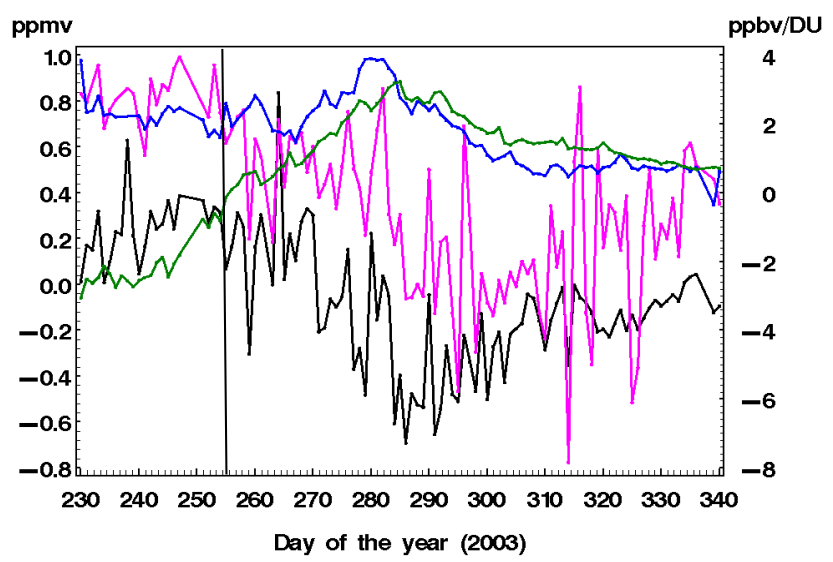

Fig. 10. Time series of passive mean $\mathrm{OmF}$ for $\mathrm{O}_{3}$ (black), $\mathrm{HNO}_{3}$ (green), and $\mathrm{NO}_{2}$ (blue) at $14.5 \mathrm{hPa}$ for the South Pole region (latitudes $>60^{\circ} \mathrm{S}$ ) during 2003. Units are ppmv for $\mathrm{O}_{3}$ and ppbv for $\mathrm{HNO}_{3}$ and $\mathrm{NO}_{2}$. The partial ozone column associated with the mean $O m F$ (in DU) is plotted in magenta. The vertical black line roughly indicates the end of the polar night.

vertical transport in the polar vortex (as shown by the dashed line in Figs. 2 through 4) combined with the presence of sunlight. The drop (increase) of the ozone mean $O m F$ is anticorrelated to the rise (drop) of the mean $O m F$ for $\mathrm{NO}_{2}$ and to a certain extent to the mean $O m F$ for $\mathrm{HNO}_{3}$ after Julian day 255 (when illumination approximately starts at the polar
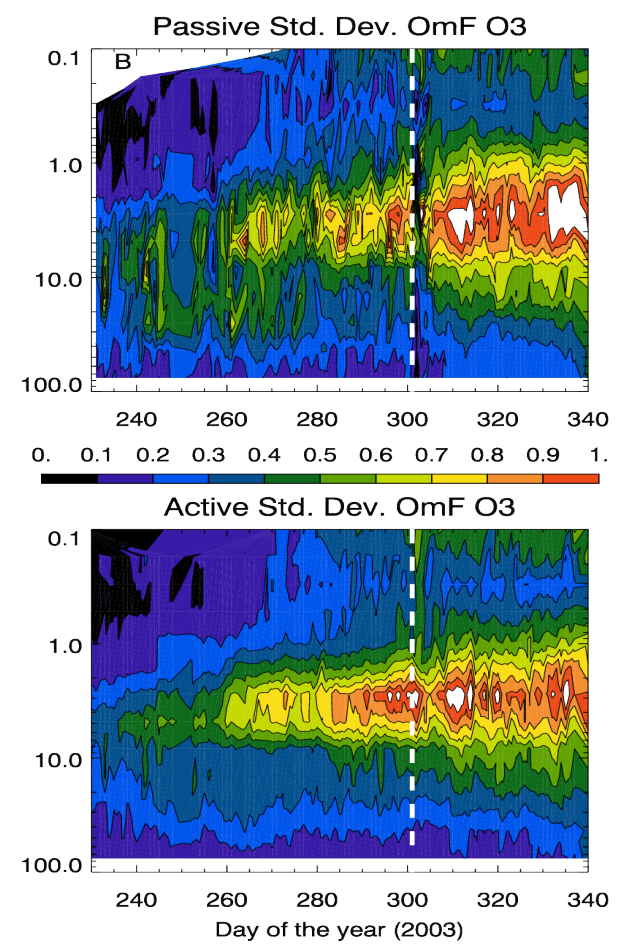

cap). The resulting time variation of the "targeted ozone partial column" (in DU units) of the mean $O m F$ between 7 and $30 \mathrm{hPa}$ is also computed and provided in Fig. 10 (magenta curve). The difference between Julian days 230-255 (during the polar night) and the period after (days 285-315 just before the vortex breakup) was found to be 5.5 $\pm 2.8 \mathrm{DU}$ (Dobson unit). This is believed to be the average impact (over about 1 month period) of the EPP-IE event on the reduction of the ozone column over the South Pole region. Table 1 summarizes the results. This estimate could be compared with an evaluation of WMO (2007) on ozone depletion where the impact due to EPP was determined to be less than about 10 DU.

We now apply the same methodology but for the SPE case. Figure 11 depicts time series of $\mathrm{O}_{3}, \mathrm{NO}_{2}$ and $\mathrm{HNO}_{3}$ and partial ozone column for the mean $O m F$ at an appropriate level (i.e., $1.585 \mathrm{hPa}$ in this case) based on plots of Fig. 9a for the North Pole region. The biggest increase of mean $O m F$ for $\mathrm{NO}_{2}$ occurs just after the SPE (Julian day 301) as expected (consistent with Figs. 6 and 7a). The "target partial column" where the depletion takes place is now from 0.5 to $4 \mathrm{hPa}$ (based on Fig. 9a). The difference between the ozone partial column mean $O m F$ before and after the SPE is evaluated, as an average, to $0.9 \pm 0.5 \mathrm{DU}$ (which is much smaller than that for the EPP-IE case). The lesser confinement in the NH polar vortex and the high altitude (near $1 \mathrm{hPa}$ ) of the ozone loss where the air density is weak explains the small impact on the ozone column. We have conducted sensitivity tests on the 
Table 1. Mean $O m F$ correlation coefficients and average ozone $O m F$ partial columns for the EPP-IE case during the polar night (before day 255) and under illumination (day 285-315).

\begin{tabular}{lccc}
\hline & Before day 255 & Day 285-315 & Difference \\
\hline $\begin{array}{l}\text { Avg. partial column of } \\
\text { mean } O m F \text { (DU): }\end{array}$ & $3.03 \pm 0.90$ & $-2.43 \pm 1.92$ & $5.5 \pm 2.8$ \\
Correlation coefficient & & & \\
for $\mathrm{NO}_{2}$ vs. $\mathrm{O}_{3}$ mean $\mathrm{OmF}$ & $0.18^{* *}$ & -0.66 & Change of sign \\
$\mathrm{HNO}_{3}$ vs. $\mathrm{O}_{3}$ & $0.34^{* *}$ & -0.63 & Idem \\
$\mathrm{NO}_{2}$ vs. $\mathrm{HNO}_{3}$ & $-0.52^{*}$ & 0.96 & Idem \\
\hline
\end{tabular}

* Correlation coefficient statistically significant with a level of confidence above $95 \%$.

* Not statistically significant above $95 \%$.

Otherwise, statistically significant above $99 \%$.

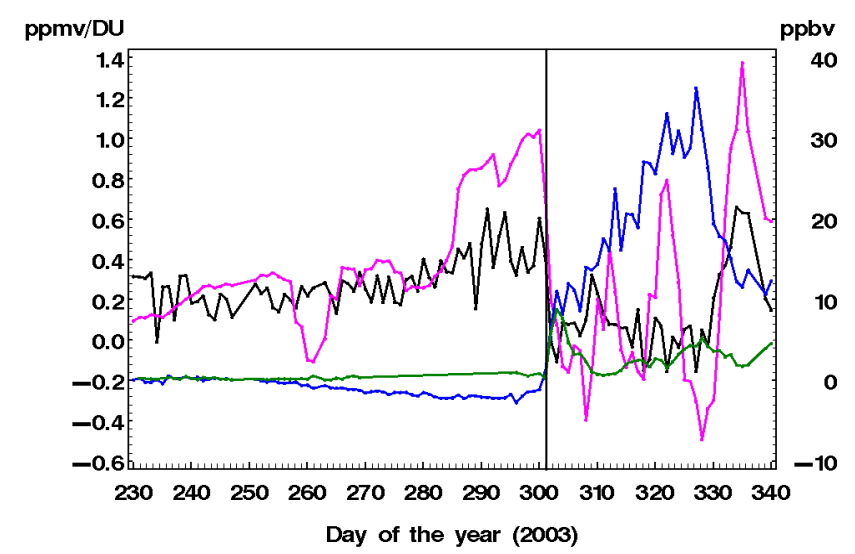

Fig. 11. Same as Fig. 10 but for the SPE case and centered at $1.585 \mathrm{hPa}$ in the North Pole region (latitude $>60^{\circ} \mathrm{N}$ ) during 2003 . The vertical blcak line roughly indicates the onset of the impact of the SPE on the stratosphere (i.e., day 301).

depth of the "target layer" used to make calculations of polar ozone loss in both cases (EPP-IE and SPE) without much difference in the results. A significant anti-correlation between mean $O m F$ for $\mathrm{NO}_{2}$ and $\mathrm{O}_{3}(R=-0.59)$ develops after the onset of SPE illustrating the role of $\mathrm{NO}_{\mathrm{x}}$ in ozone destruction. Table 2 summarizes the correlations between species for the SPE event. Note that ozone is also affected by $\mathrm{HO}_{\mathrm{x}}$ production from EPP (Reactions R3-R4, Appendix A) but the study of this family of constituents is beyond the scope of this paper since no MIPAS measurement is available in this case. In any case, its effect is transient and has a smaller impact after the end of the polar night due to their fast photochemical time scales. Note that for the same case, Vogel et al. (2008) found an ozone depletion of 3.3 DU (maximum daily average) for latitudes greater than $70^{\circ}$ (equivalent latitude). To be able to compare with this result, re-computation of ozone loss has to be done for latitudes greater than $70^{\circ}$, instead of $60^{\circ}$, and for daily average. The computation gives
1.45 DU (maximum daily average) which is still about two times less than Vogel et al. (2008) but very close to Jackman et al. (2005) who obtained about 1.5 DU for the same event. As mentioned by Vogel et al. (2008) concerning the SPE event of 2003: "on an absolute scale, the differences are small and our results support the conclusion of Jackman et al. (2005) that the impact of solar proton events on the Northern Hemisphere total polar ozone decreases is small" (end of Sect. 5 of Vogel et al., 2008, paper). Results from our study also agree with this statement. Note that the weak impact of this SPE case on the ozone column is likely to be due to a lack of synchronism with favorable meteorological conditions (see Randall et al., 2006).

An alternative method for computing the polar ozone loss would be to subtract the total column of the passive from the active case. The latter approach has been apparently successful in evaluating the polar loss due to heterogeneous chemistry in the polar vortex (Orsolini, 2008). Note however, that in this case, the signal of heterogeneous chemistry in the PSC (polar stratospheric cloud) is maximum where the weight on the total ozone column is also maximum (between 30$100 \mathrm{hPa}$ ). Since, in the context of our study, EPP-IE impacts on ozone is negligible below $30 \mathrm{hPa}$, this rather justifies the use of partial column (7-30 hPa). Moreover, the use of total column would not be accurate in our case since: (1) the signal/noise ratio of EPP impacts is likely to be low in the lower stratosphere, (2) the total column variations between the two cases (passive and active) could be due to other factors (e.g. chemistry biases, observation and retrievals errors, etc.) not linked to EPP, and (3) total column calculations are particularly sensitive to errors in the lower stratosphere where air density is higher.

The polar loss from EPP can also be estimated without any reference to chemical monitoring or assimilation as done by other authors. However, it requires either costly and complex modeling or parameterization of coupled ion-neutral chemistry, ion drag and auroral processes, non-LTE effects, shortwave heating at extreme ultraviolet wavelength (see Brasseur 
Table 2. Mean $O m F$ correlation coefficients and average ozone $O m F$ partial columns for the SPE case shortly before and after the onset of the SPE.

\begin{tabular}{lccc}
\hline & Shortly before day 301 & Day $305-332$ & Difference \\
\hline $\begin{array}{l}\text { Avg. partial column of } \\
\text { mean } O m F(\mathrm{DU})\end{array}$ & $0.86 \pm 0.14$ & $-0.05 \pm 0.34$ & $0.91 \pm 0.48$ \\
$\begin{array}{l}\text { Correlation coefficient } \\
\text { for } \mathrm{NO}_{2} \text { vs. } \mathrm{O}_{3} \text { mean } O m F\end{array}$ & $\mathrm{~N} / \mathrm{S}$ & -0.59 & $\mathrm{~N} / \mathrm{A}$ \\
$\mathrm{HNO}_{3}$ vs. $\mathrm{O}_{3}$ & $\mathrm{~N} / \mathrm{S}$ & $-0.11^{* *}$ & $\mathrm{~N} / \mathrm{A}$ \\
$\mathrm{NO}_{2}$ vs. $\mathrm{HNO}_{3}$ & $-0.63^{* *}$ & $0.27^{* *}$ & Change of sign \\
\hline
\end{tabular}

N/S: No correlation (not significant)

N/A: non applicable

* Not statistically significant above $95 \%$.

Otherwise, statistically significant above $99 \%$.

and Solomon, 2005; Jackman et al., 2008), a higher model top (at least in the MLT region), EPP sources modeling (Semeniuk et al., 2005; Jackman et al., 2008; Vogel et al., 2008; Baumgaertner et al., 2009), hydrated ion cluster chemistry (Kawa et al., 1995; de Zafra and Smyshlyaev, 2001; Brasseur and Solomon, 2005), ion-ion recombination (Aikin, 1994, 1997; Verronen et al., 2008) or involves long model integrations (Rozanov et al., 2005) or necessitates extensive multiyear comparison of observations under different meteorological conditions (Randall et al., 2006 and 2007). Use of both passive and active $O m F$ s as presented in our study could be viewed as an alternative method to existing approaches while providing significant insight on the impact of EPP events.

\section{Summary and conclusions}

The GEM-BACH coupled dynamical-chemical data assimilation system has been used to ingest MIPAS $\mathrm{NO}_{2}, \mathrm{O}_{3}$, $\mathrm{HNO}_{3}, \mathrm{CH}_{4}$ and temperature during two EPP (energetic particle precipitation) events that occurred in 2003 (EPP-IE during austral winter and SPE during boreal winter). To the best of our knowledge, it is the first time that chemical data assimilation has been successful in capturing the EPP signal within the polar vortices or elsewhere. Errera et al. (2008) have assimilated MIPAS-ESA for a longer period covering different EPP events but did not succeed in capturing $\mathrm{NO}_{\mathrm{y}}$ produced by EPP. In our study, an estimation of the error variances (based on the H-L method adapted to satellite data) and a relaxed quality control prevented the rejection of large (but valid) $\mathrm{NO}_{2}$ and $\mathrm{HNO}_{3} O m F$ residuals associated with EPP events. This demonstrates the high importance of prescribing error statistics prior to assimilation in a rigorous way and using an appropriate relaxed quality control, as was done in this study.

The chemical signature of EPP events has been analyzed and diagnosed with a new tool using both passive (without assimilation) and active (with assimilation) $O m F$ cross sections of both mean and standard deviations. The passive
$O m F$ filters out processes that the model simulates well and thus better isolates anomalies such as excesses in $\mathrm{NO}_{\mathrm{y}}$ due to EPP impacts within the polar vortices which are not provided by the model. Combined passive and active $O m F$ s offer a tool which permits an assessment of the nature of the $O m F$ residuals and their e-folding time (i.e., errors due to the initial conditions and modeling errors at various time scales). The tool also turns out to be a useful method for model and assimilation assessment. Our results indicate delays of about one month or so, identified on different occasions between the maximum $\mathrm{OmF}$ biases for $\mathrm{NO}_{2}$ and the build-up of $\mathrm{OmF}$ biases for $\mathrm{HNO}_{3}$, suggesting the possibility of the occurrence of slow time scale reactions, such as those involved in heterogeneous hydrated ion cluster chemistry. These chemical processes are absent from current stratospheric chemistry models. Finally, using a method based on the "target partial column", we were able to infer the impact of EPP on the stratospheric polar ozone loss by using time series of the passive $O m F$ biases. The average impact on the column ozone depletion for the South Pole (latitude $>60^{\circ} \mathrm{S}$ ) has been estimated to be about 5.5 DU for the EPP-IE case during Antarctic winter 2003. This represents up to $5 \%$ of the value of the total column ozone found in the ozone hole and is therefore significant. For the SPE case, the chemically induced ozone loss was modest compared to the EPP-IE and found to be about $1 \mathrm{DU}$. Therefore, despite stronger geomagnetic effects associated to SPE, the resulting ozone depletion is less important in the SPE NH case as compared to the SH EPP-IE case during austral winter. The reasons for this are linked to: (1) a weaker and less confined polar vortex in the NH than the $\mathrm{SH}$, and (2) a possible lack of favorable synchronism of meteorological conditions after the onset of the SPE favoring strong descent (see Randall et al., 2006, 2007; Seppälä et al., 2007; Siskind et al., 2007; Turunen et al., 2009). Consequently, for the SPE case, ozone depletion mostly took place in the higher stratosphere and mesosphere with a small impact on the total ozone column. Finally, one consequence of our work is that, from an assimilation point of view, slow 
time scale modeling errors or initial condition errors play a secondary role in the stratosphere since a correction of the chemical concentrations via careful assimilation is adequate to provide a realistic chemical analysis. We leave for future work the application of the methods shown in this paper for other EPP cases and also to other phenomena not included in models but captured by assimilation.

\section{Appendix A}

\section{List of important chemical reactions (discussed in the text)}

- $\mathrm{NO}_{\mathrm{x}}$ catalytic reactions

$$
\begin{aligned}
& \mathrm{NO}+\mathrm{O}_{3} \rightarrow \mathrm{NO}_{2}+\mathrm{O}_{2} \\
& \mathrm{NO}_{2}+\mathrm{O} \rightarrow \mathrm{NO}+\mathrm{O}_{2}
\end{aligned}
$$

- $\mathrm{HO}_{\mathrm{x}}$ catalytic reactions

$$
\begin{aligned}
& \mathrm{OH}+\mathrm{O}_{3} \rightarrow \mathrm{HO}_{2}+\mathrm{O}_{2} \\
& \mathrm{HO}_{2}+\mathrm{O} \rightarrow \mathrm{OH}+\mathrm{O}_{2}
\end{aligned}
$$

\section{- Ion recombination chemistry}

$$
\mathrm{H}_{2} \mathrm{O}+\mathrm{NO}_{3} \rightarrow \mathrm{HNO}_{3}+\mathrm{OH}
$$

(requires ion and darkness)

$$
\text { - Gas phase chemistry }
$$

$\mathrm{NO}_{2}+\mathrm{OH}+\mathrm{M} \rightarrow \mathrm{HNO}_{3}+\mathrm{M}$

$$
\mathrm{HNO}_{3}+\mathrm{OH} \rightarrow \mathrm{NO}_{3}+\mathrm{H}_{2} \mathrm{O}
$$

$\mathrm{HNO}_{3}+h v \rightarrow \mathrm{NO}_{3}+\mathrm{H}_{2} \mathrm{O}$

\section{- Hydrated ion cluster chemistry (time scale of about 1 month)}

$\mathrm{NO}_{2}+\mathrm{NO}_{3}+\mathrm{M} \rightarrow \mathrm{N}_{2} \mathrm{O}_{5}+\mathrm{M}$

(thermal decomposition reaction)

$\mathrm{N}_{2} \mathrm{O}_{5}+\mathrm{H}_{2} \mathrm{O}$ (ion cluster) $\rightarrow 2 \mathrm{HNO}_{3}$

Acknowledgements. The authors wish to thank ESA contract officer Tobias Weir for his direction and encouragements during our early work on this paper (through an European Space Agency contract), Paul-André Beaulieu for converting MIPAS observations in the appropriate format, Alexander Kallaur and Vivian Lee for their work on the chemistry interface of the GEM-BACH model, Frédérick Chosson for his assistance with the graphs and two anonymous referees for their valuable comments.

Edited by: P. Jöckel

\section{References}

Aikin, A. C.: Energetic particle-induced enhancements of stratospheric nitric acid, Geophys. Res. Lett., 21(10), 859-862, 1994.

Aikin, A. C.: Production of stratospheric $\mathrm{HNO}_{3}$ by different ionmolecule reaction mechanisms, J. Geophys. Res., 102(D11), 12921-12925, 1997.

Baier, F., Erbertseder, T., Morgenstern, O., Bittner, M., and Brasseur, G.: Assimilation of MIPAS observations using a threedimensional global chemistry-transport model, Q. J. Roy. Meteor. Soc., 613, 3529-3542, 2005.

Baker, D. N., Kanekal, S. G., Li, X., Monk, S. P., Goldstein, J., and Burch, J. L.: An extreme distortion of the Van Allen belt arising from the "Hallowe'en" solar storm in 2003, Nature, 432, 878-880, 2004.

Batchelor, R., Strong, K., Lindenmaier, R., Manson, A., Meek, C. Manney, G., Daffer, W., Polavarapu, S., Reszka, M., Neish, M., Robichaud, A., et al.: Understanding the Arctic stratosphere during IPY through a combination of ground-based measurements, models and dynamical analyses, Presentation to AGU 2009, Joint Assembly, 24-27 May, Toronto, Canada, 2009.

Baumgaertner, A. J. G., Jöckel, P., and Brühl, C.: Energetic particle precipitation in ECHAM5/MESSy1 - Part 1: Downward transport of upper atmospheric $\mathrm{NO}_{\mathrm{x}}$ produced by low energy electrons, Atmos. Chem. Phys., 9, 2729-2740, 2009,

http://www.atmos-chem-phys.net/9/2729/2009/.

Brasseur, G. and Solomon, S.: Aeronomy of the Middle Atmosphere: Chemistry and Physics of the Stratosphere and Physics of the Stratosphere and Mesosphere, Third revised and enlarged ed., Springer, ISBN 978-1-4020-3284-4, 2005.

Callis, L. B., Baker, D. N., Natarajan, M., Blake, J. B., Mewaldt, R. A., Selesnick, R., and Cummings, J. R.: A 2-D model simulation of downward transport of $\mathrm{NO}_{\mathrm{y}}$ into the stratosphere: Effects on the 1994 austral spring $\mathrm{O}_{3}$ and $\mathrm{NO}_{\mathrm{y}}$, Geophys. Res. Lett., 23, 1905-1908, 1996.

Cortesi, U., Lambert, J. C., De Clercq, C., Bianchini, G., Blumenstock, T., Bracher, A., Castelli, E., Catoire, V., Chance, K. V., De Mazière, M., Demoulin, P., Godin-Beekmann, S., Jones, N., Jucks, K., Keim, C., Kerzenmacher, T., Kuellmann, H., Kuttippurath, J., Iarlori, M., Liu, G. Y., Liu, Y., McDermid, I. S., Meijer, Y. J., Mencaraglia, F., Mikuteit, S., Oelhaf, H., Piccolo, C., Pirre, M., Raspollini, P., Ravegnani, F., Reburn, W. J., Redaelli, G., Remedios, J. J., Sembhi, H., Smale, D., Steck, T., Taddei, A., Varotsos, C., Vigouroux, C., Waterfall, A., Wetzel, G., and Wood, S.: Geophysical validation of MIPAS-ENVISAT operational ozone data, Atmos. Chem. Phys., 7, 4807-4867, 2007, http://www.atmos-chem-phys.net/7/4807/2007/.

Côté, J., Gravel, S., Méthot, A., Patoine, A., Roch, M., and Staniforth, A. N.: The operational CMC-MRB Global Environmental Multiscale (GEM) model, Part I: design considerations and formulation, Mon. Weather Rev., 126, 1373-1395, 1998.

Daley, R.: Atmospheric data analysis, Cambridge University Press, 1991.

Damian, V., Sandu, A., Damian, M., Potra, F., and Carmichael, G. R.: The kinetic preprocessor KPP - a software environment for solving chemical kinetics, Comput. Chem. Eng., 26, 1567-1579, 2002.

Dee, D. P. and da Silva, A. M.: Data assimilation in the presence of forecast bias, Q. J. Roy. Meteor. Soc., 124, 269-295, 1998. 
de Grandpré, J., Ménard, R., Rochon, Y. J., Charrette, C., Chabrillat, S., and Robichaud, A.: Predictability of coupled chemistrydynamics data assimilation, Mon. Weather Rev., 137, 679-692, 2009.

Dethof, A.: Assimilation of ozone retrievals from the MIPAS instrument on board ENVISAT, ECMWF Technical Memorandum, 428, 2003.

Dethof, A., Geer, A., Lahoz, W., Goutail, F., Bazureau, A., Wang, D. Y., and von Clarmann, T.: MIPAS temperature validation by the MASI group, ESA, in: Proceedings of the Second Workshop on the Atmospheric Chemistry Validation of ENVISAT (ACVE2), ESA-ESRIN, Frascati, Italy (ESA SP-562), 3-7 May 2004, 23.1-23.5, 2004.

de Zafra, R. and Smyshlyaev, S. P.: On the formation of $\mathrm{HNO}_{3}$ in the Antarctic mid to upper stratosphere in winter, 106(23), 23115-23125, 2001.

Errera, Q. and Fonteyn, D.: Four-dimensional variational chemical assimilation of CRISTA stratospheric measurements, J. Geophys. Res., 106, 12253-12265, 2001.

Errera, Q., Daerden, F., Chabrillat, S., Lambert, J. C., Lahoz, W. A., Viscardy, S., Bonjean, S., and Fonteyn, D.: 4D-Var assimilation of MIPAS chemical observations: ozone and nitrogen dioxide analyses, Atmos. Chem. Phys., 8, 6169-6187, 2008,

http://www.atmos-chem-phys.net/8/6169/2008/.

ESA (European Space Agency): ENVISAT, MIPAS, An instrument for atmospheric chemistry and climate research, ESA Publications Division, ESTEC, P.O. Box 299, 2200 AG Noordwijk, The Netherlands, SP-1229, 2000.

Fischer, H. and Oelhaf, H.: Remote sensing of vertical profiles of atmospheric trace constituents with MIPAS limb-emission spectrometers, Appl. Optics, 35, 2787-2796, 1996.

Fischer, H., Birk, M., Blom, C., Carli, B., Carlotti, M., von Clarmann, T., Delbouille, L., Dudhia, A., Ehhalt, D., Endemann, M., Flaud, J. M., Gessner, R., Kleinert, A., Koopman, R., Langen, J., López-Puertas, M., Mosner, P., Nett, H., Oelhaf, H., Perron, G., Remedios, J., Ridolfi, M., Stiller, G., and Zander, R.: MIPAS: an instrument for atmospheric and climate research, Atmos. Chem. Phys., 8, 2151-2188, 2008,

http://www.atmos-chem-phys.net/8/2151/2008/.

Funke, B., López-Puertas, M., Gil-López, S., von Clarmann, T., Stiller, G. P., Fischer, H., and Kellmann, S.: Downward transport of upper atmospheric $\mathrm{NO}_{\mathrm{x}}$ into the polar stratosphere and lower mesosphere during the Antarctic 2003 and Arctic 2002/2003 winters, J. Geophys. Res., 110, D24308, doi:10.10129/2005JD006463, 2005.

Gauthier, P., Charrette, C., Fillion, L., Koclas, P., and Laroche, S: Implementation of a 3D variational data assimilation system at the Canadian Meteorological Centre, Part I: The global analysis, Atmos. Ocean, 37, 103-156, 1999.

Gauthier, P., Chouinard, C., and Brasnett, B.: Quality control: Methodology and applications, in: Data Assimilation for the Earth System, edited by: Swinbank, R., Shutyaev, V., and Lahoz, W. A., NATO Science Series IV: Earth and Environment Science, Kluwer Academic Publishers, 26, 177-187, 2003.

Hairer, E. and Wanner, G.: Solving ordinary differential equations 2 - Stiff and differential-algebraic problems, Springer series in computational mathematics, Springer, Second edition, Vol. 14, 1996.
Hollingsworth, A. and Lönnberg, P.: The statistical structure of short-range forecast errors as determined from radiosonde data, Part I. The wind field, Tellus, 38A, 111-136, 1986.

Jackman, C. H., McPeters, R. D., Labow, G. J., Fleming, E. L., Praderas, C. J., and Russell, J. M.: Northern hemisphere atmospheric effects due to the July 2000 Solar Proton Event, Geophys. Res. Lett., 28(1), 2883-2886, 2001.

Jackman, C. H. and McPeters, R. D.: The Effect of Solar Proton Events on Ozone and Other Constituents, in: Solar Variability and its Effects on Climate, edited by: Pap, J. M., Fox, P., Frohlich, C., Hudson, H. S., Kuhn, J., McCormack, J., North, G., Sprigg, W., and Wu, S. T., AGU, Washington, D.C., Geoph. Monog. Series, 141, 305-319, 2004.

Jackman, C. H., DeLand, M. T., Labow, G. J., Fleming, E. L., Weisenstein, D. K., Ko, M. K. W., Sinnhuber, M., and Russell, J. M.: Neutral atmospheric influences of the solar proton events in October-November 2003, J. Geophys. Res., 110, A09S27, doi:10.1029/2004JA010888, 2005.

Jackman, C. H., Marsh, D. R., Vitt, F. M., Garcia, R. R., Fleming, E. L., Labow, G. J., Randall, C. E., López-Puertas, M., Funke, B., von Clarmann, T., and Stiller, G. P.: Short- and medium-term atmospheric constituent effects of very large solar proton events, Atmos. Chem. Phys., 8, 765-785, 2008,

http://www.atmos-chem-phys.net/8/765/2008/.

Kalnay, E.: Atmospheric Modeling, Data Assimilation and Predictability, Cambridge University Press, 2003.

Kawa, S. R., Kumer, J. B., Douglass, A. R., Roche, A. E., Smith, S. E., Taylor, F. W., and Allen, D. J.: Missing chemistry of reactive nitrogen in the upper stratospheric polar winter, Geophys. Res. Let., 22, 2629-2632, 1995.

López-Puertas, M., Funke, B., Gil-López, S., von Clarmann, T., Stiller, G. P., Höpfner, M., Kellmann, S., Fischer, H., and Jackman, C. H.: Observation of $\mathrm{NO}_{\mathrm{x}}$ enhancement and ozone depletion in the Northern and Southern Hemispheres after the October-November 2003 solar proton events, J. Geophys. Res., 110, A09S43, doi:10.1029/2005JA011050, 2005.

Manney, G. L., Zurek, R. W., O’Neill, A., and Swinbank, R.: On the motion of air through the stratospheric polar vortex, J. Atmos. Sci., 51, 2973-2994, 1994.

Manney, G. L., Krüger, K., Sabutis, J. L., Sena, S. A., and Pawson, S.: The remarkable 2003-2004 winter and other recent warm winters in the Arctic stratosphere since the late 1990s, J. Geophys. Res., 110, D04107, doi:10.10129/2004JD005367, 2005.

McDonald, M. R. L., de Zafra, R., and Muscari, G.: Millimiter wave spectroscopic measurements over the South Pole, 5, Morphology and evolution of $\mathrm{HNO}_{3}$ vertical distribution, 1993 versus 1995 , J. Geophys. Res., 105, 17739-17750, 2000.

Ménard, R., Gauthier, P., de Grandpré, J., Robichaud, A., Rochon, Y., Chabrillat, S., Fonteyn, D., von Clarmann, T., Yang, Y., Charron, M., McConnell, J., Kaminski, J., Vaillancourt, P., Charrette, C., and Kallaur, A.: Coupled chemical-dynamical data assimilation, executive summary available at http://esamultimedia.esa. int/docs/gsp/completed/C18560ExS.pdf, last access: 10 February 2010, ESA/ESTEC Contract No. 18560/04/NL/FF, 2007.

Ménard, R.: Bias estimation, in: Data assimilation, edited by: Lahoz, W., Khattatov, B., and Ménard, R., Springer, 2009. 
Orsolini, Y. J., Manney, G. L., Santee, M., Randall, C. E.: An upper stratospheric layer of enhanced $\mathrm{HNO}_{3}$ following exceptional solar storms, Geophys. Res. Lett., 32(12), L12S01, doi:10.129/2004GL021588, 2005.

Orsolini, Y. J.: Arctic ozone loss inferred from assimilation of MLS and SBUV observations, 37th COSPAR Scientific Assembly, Montreal, Canada, 13-20 July 2008, A11-0078-08, 2008.

Parrish, D. F. and Derber, J. C.: The National Meteorological Center's Spectral Statistical-Interpolation Analysis System, Mon. Weather Rev., 120, 1747-1763, 1992.

Polavarapu, S., Ren, S., Rochon, Y., Sankey, D., Ek, N., Koshyk, J., and Tarasick, D.: Data assimilation with the Canadian Middle Atmosphere Model, Atmos. Ocean, 43(1), 77-100, 2005.

Randall, C. E., Harvey, V. L., Singleton, C. S., Bernath, P. F., Boone, C. D., and Kozyra, J. U.: Enhanced $\mathrm{NO}_{\mathrm{x}}$ in 2006 linked to strong upper stratospheric Arctic vortex, Geophys. Res. Lett., 33, L18811, doi:10.1029/2006GL027160, 2006.

Randall, C. E., Harvey, V. L., Singleton, C. S., Bailey, S. M., Bernath, P. F., Codrescu, M., Nakajima, H., and Russell, J. M.: Energetic particle precipitation effects on the Southern Hemisphere stratosphere in 1992-2005, J. Geophys. Res., 112, D08308, doi:10.1029/2006JD007696, 2007.

Ridolfi, M., Blum, U., Carli, B., Catoire, V., Ceccherini, S., Claude, H., De Clercq, C., Fricke, K. H., Friedl-Vallon, F., Iarlori, M., Keckhut, P., Kerridge, B., Lambert, J.-C., Meijer, Y. J., Mona, L., Oelhaf, H., Pappalardo, G., Pirre, M., Rizi, V., Robert, C., Swart, D., von Clarmann, T., Waterfall, A., and Wetzel, G.: Geophysical validation of temperature retrieved by the ESA processor from MIPAS/ENVISAT atmospheric limb-emission measurements, Atmos. Chem. Phys., 7, 4459-4487, 2007, http://www.atmos-chem-phys.net/7/4459/2007/.

Rinsland, C. P., Boone, C., Nassar, R., Walker, K., Bernath, P., McConnell, J. C., and Chiou, L.: Atmospheric Chemistry Experiment (ACE), Arctic stratospheric measurements of $\mathrm{NO}_{\mathrm{x}}$ during February and March 2004: Impact of intense solar flares, Geophys. Res. Lett., 32, L16S05, doi:10.1029/2005GL022425, 2005.

Rozanov, E., Callis, L., Schlesinger, M., Yang, F., Andronova, N., and Zubov, V.: Atmospheric response to $\mathrm{NO}_{\mathrm{y}}$ source due to energetic electron precipitation, Geophys. Res. Lett., 32, L14811, doi:1029/2005GL023041, 2005.

Sander, S. P., Friedl, R. R., Golden, D. M., Kurylo, M. J., Huie, R. E., Orkin, V. L., Moortgaat, G. K., Ravishankara, A. R., Kolb, C. E., Molina, M. J., and Finlayson-Pitts, B. J.: Chemical Kinetics and Photochemical Data for Use in Atmospheric Studies, Evaluation Number 14, Publication 02-25, JPL, 2003.

Semeniuk, K., McConnell, J. C., and Jackman, C. H.: Simulation of the October-November 2003 solar proton events in the CMAM GCM: Comparison with observations, Geophys. Res. Lett., 32, L15S02, doi:10.1029/2005GL022392, 2005.

Seppälä, A., Verronen, P. T., Kyrölä, E., Hassinen, S., Backman, L., Hauchecorne, A., Bertaux, J. L., and Fussen, D.: Solar proton events of October-November 2003: Ozone depletion in the Northern Hemisphere polar winter as seen by GOMOS/Envisat, Geophys. Res. Lett., 31(19), L19107, doi:10.1029/2004GL021042, 2004.

Seppälä, A., Verronen, P. T., Cliverd, M. A., et al.: Arctic and Antarctic polar vortex $\mathrm{NO}_{\mathrm{x}}$ and energetic particle precipitation in 2002-2006, Geophys. Res. Lett., 34, L12810,
doi:10.1029/2007GL029733, 2007.

Sinnhuber, B.-M., von der Gathen, P., Sinnhuber, M., Rex, M., König-Langlo, G., and Oltmans, S. J.: Large decadal scale changes of polar ozone suggest solar influence, Atmos. Chem. Phys., 6, 1835-1841, 2006,

http://www.atmos-chem-phys.net/6/1835/2006/.

Siskind, D. E., Nedoluha, G. E., Randall, C. E., Fromm, M., and Russell III, J. M.: An assessment of Southern Hemisphere stratospheric $\mathrm{NO}_{\mathrm{X}}$ enhancements due to transport from the upper atmosphere, Geophys. Res. Lett., 27, 329-332, 2000.

Siskind, D. E., Eckermann, S. D., Coy, L., McCormack, J. P., and Randall, C. E.: On recent interannual variability of the Arctic winter mesosphere: Implications for tracer descent, Geophys. Res. Lett., 34, L09806, doi:10.1029/2007GL029293, 2007.

Solomon, S. and Crutzen, P. J.: Analysis of the August 1972 solar proton event including chlorine chemistry, J. Geophys. Res., 86, 1140-1151, 1981.

Stiller, G. P., Gizaw, M. T., von Clarmann, T., Glatthor, N., Höpfner, M., Kellmann, S., Linden, A., Ruhnke, R., Fischer, H., López-Puertas, M., Funke, B., and Gil-López, S.: An enhanced $\mathrm{HNO}_{3}$ second maximum in the Antarctic midwinter upper stratosphere 2003, J. Geophys. Res., 110, D20303, doi:10.1029/2005JD006011, 2005.

Turunen, E., Verronen, P. T., Seppälä, A., Rodger, C. J., Clilverd, M. A., Tamminen, J., Enell, C. F., and Ulich, T.: Impact of different energies of precipitating particles on $\mathrm{NO}_{\mathrm{x}}$ generation in the middle and upper atmosphere during geomagnetic storms, J. Atmos. Sol.-Terr. Phy., 71, 1176-1189, doi:10,1016/j.jastp.2008.07.05, 2009.

Verronen, P. T., Funke, B., López-Puertas, M., Stiller, G. P., von Clarmann, T., Glatthor, N., Enell, C.-F., Turunen, E., and Tamminen, $\mathrm{J}$.: About the increase of $\mathrm{HNO}_{3}$ in the stratopause region during the Halloween 2003 solar proton event, Geophys. Res. Lett., 35, L20809, doi:10,1029/2008GL035312, 2008.

Vogel, B., Konopka, P., Grooß, J.-U., Müller, R., Funke, B., LópezPuertas, M., Reddmann, T., Stiller, G., von Clarmann, T., and Riese, M.: Model simulations of stratospheric ozone loss caused by enhanced mesospheric $\mathrm{NO}_{\mathrm{x}}$ during Arctic Winter 2003/2004, Atmos. Chem. Phys., 8, 5279-5293, 2008, http://www.atmos-chem-phys.net/8/5279/2008/.

von Clarmann, T.: Personal discussion at ESTEC, The Netherlands, 2007.

Wang, D. Y., von Clarmann, T., Fischer, H., et al.: Validation of stratospheric temperatures measured by Michelson Interferometer for Passive Atmospheric Sounding (MIPAS) on Envisat, J. Geophys. Res., 110, D08301, doi:10.1029/2004JD005342, 2005.

Wetzel, G., Bracher, A., Funke, B., Goutail, F., Hendrick, F., Lambert, J.-C., Mikuteit, S., Piccolo, C., Pirre, M., Bazureau, A., Belotti, C., Blumenstock, T., De Mazière, M., Fischer, H., Huret, N., Ionov, D., López-Puertas, M., Maucher, G., Oelhaf, H., Pommereau, J.-P., Ruhnke, R., Sinnhuber, M., Stiller, G., Van Roozendael, M., and Zhang, G.: Validation of MIPAS-ENVISAT $\mathrm{NO}_{2}$ operational data, Atmos. Chem. Phys., 7, 3261-3284, 2007, http://www.atmos-chem-phys.net/7/3261/2007/.

WMO: Scientific Assessment of Ozone Depletion: 2006, Global Ozone Research and Monitoring, Project - Report No. 50, World Meteorological Organization, Geneva, 2007. 